FEDERAL RESERVE BANK OF SAN FRANCISCO

WORKING PAPER SERIES

\title{
Beveridge Curve Shifts across Countries since the Great Recession
}

\author{
Bart Hobijn, \\ Federal Reserve Bank of San Francisco, \\ VU University Amsterdam, and Tinbergen Institute, \\ Aysegul Sahin, \\ Federal Reserve Bank of New York
}

July 2013

Working Paper 2012-24

http://www.frbsf.org/publications/economics/papers/2012/wp12-24bk.pdf

The views in this paper are solely the responsibility of the authors and should not be interpreted as reflecting the views of the Federal Reserve Bank of San Francisco or the Board of Governors of the Federal Reserve System. 


\title{
Beveridge Curve Shifts across Countries since the Great Recession
}

\author{
BART HOBIJN \\ Federal Reserve Bank of SAN Francisco ${ }^{1}$ \\ VU UNIVERSITY AMSTERDAM, \\ AND TINBERGEN INSTITUTE
}

\author{
AYŞEGÜL ŞAHİN \\ FEDERAL ReSERVE BANK OF New York
}

July 20, 2013.

\begin{abstract}
We document the shift in the Beveridge curve in the U.S. since the Great Recession. We argue that a decline in quits, the relatively poor performance of the construction sector, and the extension of unemployment insurance benefits have largely driven this shift. We then introduce a method to estimate fitted Beveridge curves for other OECD countries for which data on vacancies and employment by job tenure are available. We show that Portugal, Spain, and the U.K. also experienced rightward shifts in their Beveridge curves. Besides the U.S., these are among the countries with the highest house price and construction employment declines in our sample.
\end{abstract}

$\begin{array}{ll}\text { Keywords: } & \text { Cross-country analysis, Great Recession, labor market dynamics. } \\ \text { JEL-codes: } & \text { J2, O5, E32. }\end{array}$

\footnotetext{
1 We are grateful to Timothy Ni for his excellent research assistance. The views expressed in this paper solely reflect those of the authors and not necessarily those of the Federal Reserve Bank of San Francisco, Federal Reserve Bank of New York, nor those of the Federal Reserve System as a whole. Contact information: Bart Hobijn: bart.hobijn@ @sf.frb.org, Ayşegül Şahin: aysegul.sahin@ny.frb.org
} 


\section{Introduction}

Since the onset of the Great Recession, there has been a change in the relationship between the unemployment rate and vacancy rate in the U.S. This relationship, summarized by the Beveridge curve, was remarkably stable from 2000 through 2007, even during the 2001 recession. However, since the summer of 2009 the vacancy rate has trended upwards while the unemployment rate has only come down slightly. In fact, in June 2012 the job openings rate in the U.S. was back to its June 2008 level, before the depth of the financial crisis. The unemployment rate, however, was 2.7 percentage points higher than in June 2008. This change in the relationship between the unemployment and vacancy rates caused a rightward shift in the Beveridge curve.

The availability of data on hires, quits, and layoffs, from the Job Openings and Labor Turnover Survey (JOLTS), has allowed us to examine this rightward shift in detail. The rightward shift of the U.S. Beveridge curve is a consequence of firms hiring fewer workers per job opening than one would expect given the historical regularities (Barnichon et al. (2012)). This is often interpreted as an increase in labor market frictions or, equivalently, a decline in the efficiency with which workers and employers get matched in the U.S. labor market. ${ }^{2}$

The housing-driven recession in the U.S. resulted in a shift in the composition of labor demand away from occupations with high labor turnover, like those in construction, to occupations with low labor turnover and few hires per vacancy, like those in medical care and engineering. This composition effect alone resulted in a decline in measured match efficiency in the U.S. The decline was amplified because the shift in labor demand together with the disproportionate layoffs in occupations for which labor demand declined resulted in an increased mismatch between the skills demanded and those supplied by the unemployed. In response to the deep recession, unemployment insurance benefits were extended, further contributing to the decline in match efficiency. The effect of the decline of match efficiency on the Beveridge curve was partly offset by a decline in quits, resulting in the need for fewer hires and vacancies to maintain the same unemployment rate.

In this paper, we study the Beveridge curves and recent labor market outcomes of a large set of countries to compare and contrast their experiences with those of the U.S. Specifically, we quantify

\footnotetext{
${ }^{2}$ Several recent studies have estimated the magnitude of this decline in match efficiency. Among them BorowczykMartins et al. (2013), Barnichon et al. (2012), Davis, Faberman, and Haltiwanger (2012), and Sedláček (2012).
} 
deviations from the Beveridge curve for 13 OECD countries, including the U.S., since the Great Recession.

In order to quantify the recent deviations from the Beveridge curve for different countries, we introduce a new method, based on the one used in Barnichon et al. (2012), to construct fitted Beveridge curves for OECD countries for which data on vacancies and employment by job tenure are available. These fitted Beveridge curves are calculated as the vacancy rate at which the unemployment rate is equal to its turnover-steady-state value. The turnover steady state is the one in which hires minus separations as a fraction of employment equals the growth rate of the labor force.

The advantage of using this method to construct fitted Beveridge curves, as opposed to estimating a non-linear relationship between the unemployment and vacancy rates, is that it directly relates shifts in Beveridge curves across countries to estimates of declines of underlying match efficiency and labor turnover. ${ }^{3}$ Thus, our method provides a direct empirical link between movements in the Beveridge curve and measures of changes in labor market frictions. Our method consists of three steps.

First, we derive estimates of total hires and separations in each country in a year from annual data on the distribution of employees by job tenure. These estimates can be interpreted in the same way as the hires and separations measures for the U.S. from the JOLTS. Second, given the estimates of labor turnover in a year, we then estimate how the number of hires per vacancy, known as the vacancy yield, fluctuated with the number of unemployed persons per vacancy before the onset of the Great Recession. This method provides us with estimates of the matching functions for the countries in our sample. In addition, we also estimate how separations comoved with labor market tightness. Finally, having obtained how hires and separations comove with the unemployment and vacancy rates, we solve for those combinations of these rates that satisfy the turnover steady-state condition. These combinations are the fitted pre-2008 Beveridge curves. We then compare these estimated curves with the actual realized unemployment and vacancy rates both before the Great Recession as well as during and afterwards.

We find that the fitted Beveridge curves provide a good description of the actual unemployment and vacancy rate relationship in the countries in our sample for the 15 years preceding the Great

\footnotetext{
${ }^{3}$ Non-linear regressions are the most common empirical method of studying Beveridge curves. See Nickell et al. (2001), Valletta (2005), Bouvet (2012), and Bonthuis et al. (2013) for example.
} 
Recession. This proves the usefulness of interpreting the Beveridge curve in terms of a laborturnover steady-state relationship.

For the observations during and after the Great Recession, we find that, besides the U.S., there are three other countries in our sample of 13 that seem to have experienced a rightward shift in their Beveridge curves: Portugal, Spain, and the U.K. The other countries in our sample, i.e. Australia, Austria, Belgium, France, Germany, Japan, the Netherlands, Norway, and Switzerland, seem to continue to be close to or on the Beveridge curve that they were on before 2008. What Portugal, Spain, and the U.K. have in common with the U.S. is that they all saw a disproportionate decline in construction employment, which in Spain and the U.K., just like in the U.S., occurred on the heels of large declines in housing prices.

Finally, to put the recent Beveridge curve shifts in historical context, we compute the magnitude of Beveridge curve shifts that took place between 75-85 and 91-07 in many of the countries in our sample. These shifts were much larger than those observed since the Great Recession. In particular, (changes in) labor market institutions and policies played an important role in the amplification and proliferation of these shifts in Continental Europe as compared to Anglo-Saxon and Scandinavian countries (Blanchard and Wolfers, 2000, Nickell et al., 2001).

The structure of the rest of this paper is as follows. In Section 2 we review the evidence on the U.S. Beveridge curve and its rightward shift since the summer of 2009. In Section 3, we introduce our method to construct annual time series of labor market turnover for OECD countries and use these estimates of hires and separations to construct fitted pre-Great-Recession Beveridge curves for the 14 countries in our sample. We then compare these curves to the outcomes, in terms of the unemployment and vacancy rates, since 2008. This allows us to estimate the Beveridge curve shifts across countries since the Great Recession. In Section 4, we line the shifts in the Beveridge curves since the start of the Great Recession up against evidence on the potential causes of the shifts and compare them to the shifts that occurred between the mid-1980's and 2000's. Finally, we conclude with Section 5. We discuss the data and most important equations we use in the main text. More detailed derivations of the equations can be found in Appendix A. 


\section{U.S. Beveridge curve shift since the Great Recession}

Figure 1 shows the U.S. Beveridge curve from December 2000 through June 2012. It plots the unemployment rate against the job openings rate. The black dots are monthly observations before the Great Recession, while the squares are observations from January 2008 onwards.

The black dots show a clear pre-Great-Recession relationship between the unemployment and vacancy rates: a stable Beveridge curve. During the Great Recession, there was a steep decline in labor demand, reflected by a drop in the vacancy rate that led to a run up in the unemployment rate. However, in June 2012 the vacancy rate had recovered to its June 2008 level, while the unemployment rate was still more than 2.5 percentage points higher than in the summer of 2008 . Thus, the stable pre-recession Beveridge curve had fallen apart; for a given vacancy rate, the unemployment rate is now several percentage points higher than it was before the recession.

As Tasci and Lindner (2010) point out, temporary deviations from the Beveridge curve in which unemployment is high relative to the level of vacancies have been commonplace in the U.S. In fact, Mortensen (1994) points out that counter-clockwise loops in the unemployment vacancy relationship are a feature of the transitional dynamics of labor market models with search frictions. However, the recent deviation from the pre-recession Beveridge curve has been continuing for more than three years. That is much longer than the duration of counter-clockwise loops implied by the search model that is analyzed in Mortensen (1994). This observation suggests that the rightward shift of the U.S. Beveridge curve since mid-2009 is likely to be a persistent shift. In order to assess how persistent the shift is, it is important to understand what drives it.

\section{The Beveridge curve as a turnover-steady-state relationship}

The drivers of the Beveridge curve shift are best understood by interpreting the curve as the steadystate relationship between the unemployment and vacancy rates at which net hiring offsets the flows into and out of the labor force such that the unemployment rate is constant (see Barnichon et al., 2012). ${ }^{4}$ This interpretation directly relates movements in the Beveridge curve to changes in underlying labor market frictions.

\footnotetext{
${ }^{4}$ Labor turnover, as in hires and separations, includes job-to-job transitions. This is in contrast to Budd et al. (1987) and Barnichon and Figura (2010) which define the Beveridge curve in terms of the flow-steady-state of unemployment in which inflows into and outflows from unemployment are equal.
} 
Since the total number of unemployed persons, $U_{t}$, is equal to the size of the labor force, $L F_{t}$, minus those employed, $E_{t}$, we can write the change in unemployment as the change in the labor force minus the change in employment:

$$
\Delta U_{t+1}=\Delta L F_{t+1}-\Delta E_{t+1}=\Delta L F_{t+1}-H_{t}+S_{t}
$$

Note that the second equality is obtained by using the observation that the change in employment equals the difference between hires $\left(H_{t}\right)$ and separations $\left(S_{t}\right)$.

Rearranging the above equation yields that the change in the unemployment rate, $u_{t}=U_{t} / L F_{t}$, is proportional to the difference between the growth rate, $g_{t+1}=\left(L F_{t+1}-L F_{t}\right) / L F_{t}$, of the labor force and that of employment, given by $\left(H_{t}-S_{t}\right) / E_{t}$. In particular,

$$
\Delta u_{t+1}=\frac{1-u_{t}}{1+g_{t+1}}\left(g_{t+1}-\frac{H_{t}}{E_{t}}+\frac{S_{t}}{E_{t}}\right)
$$

Hence, the unemployment rate does not change whenever the growth rate of employment equals the growth rate of the labor force. That is, the labor market is in its turnover steady state when

$$
g_{t+1}=\frac{H_{t}}{E_{t}}-\frac{S_{t}}{E_{t}}
$$

The above turnover steady-state condition is not written as a function of the unemployment and vacancy rates. We introduce them by assuming that the number of hires per vacancy, known as the vacancy yield, is a function of the ratio of the number of unemployed per vacancy. That is, if there are a lot of unemployed persons per vacancy, i.e. there is a lot of slack in the labor market, then it is relatively easy for employers to fill job openings. Since measured vacancies are a stock and hires a flow, this would show up in the data as a high number of hires per vacancy. The opposite is true in case the labor market is tight and there are very few unemployed persons per job opening.

In particular, we assume the common functional form (Petrongolo and Pissarides, 2001) of a Cobb-Douglas matching function and write hires per vacancy $\left(H_{t} / V_{t}\right)$ as

$$
\ln \left(H_{t} / V_{t}\right)=\mu_{h}+\alpha_{h} \ln \left(U_{t} / V_{t}\right)+\varepsilon_{h, t},
$$

where $V_{t}$ is the number of vacancies, $\mu_{h}$ is the average match efficiency and $\varepsilon_{h, t}$ reflects the deviation from the Cobb-Douglas relationship at time $t$.

Brügemann (2008) notes that there is a puzzling discrepancy between estimates of $\alpha_{h}$ obtained from matching functions and from fitting Beveridge curves. The reason for this is that it is not only 
hires per vacancy, $H_{t} / V_{t}$, that move with labor market tightness and that drive fluctuations in the hires rate, $H_{t} / E_{t}$. The separation rate, $H_{t} / V_{t}$, also comoves with the unemployment to vacancy ratio. Hence, estimates of $\alpha_{h}$ obtained from fitting Beveridge curves that ignore these movements in the separation rate soak up these movements as part of the matching function elasticity. In order to overcome this problem, we construct our fitted Beveridge curves by specifically taking into account the comovements of the separations rate with the vacancy-to-unemployment ratio. ${ }^{5}$

Separations consist of layoffs and quits, which move in opposite directions over the business cycle. When the labor market is tight, and there are few unemployed persons and a lot of vacancies, layoffs are rare but many people quit and switch from one job to another (Akerlof, Rose, and Yellen, 1988). During recessions and recoveries, when there is a lot of slack in the labor market, layoffs tend to be elevated (especially in early stages of recessions), switching jobs becomes harder, and quits decline.

Given these two opposite cyclical patterns for layoffs and quits, the cyclicality of separations as a whole depends on which of them dominates. Hall (2005) argues that these two effects approximately offset each other in the U.S. and that, as a result, the separation rate moves little over the business cycle. However, the JOLTS data that have become available since Hall's (2005) conjecture suggest that the quits effect dominates and that the U.S. separation rate is procyclical.

To allow for cyclicality in the separation rate, we postulate the following functional form for the cyclicality of separations: ${ }^{6}$

$$
\ln \left(S_{t} / E_{t}\right)=\mu_{s}+\alpha_{s} \ln \left(U_{t} / V_{t}\right)+\varepsilon_{s, t}
$$

If $\alpha_{s}>0$, then separations are countercyclical and the layoffs effect dominates. When $\alpha_{s}<0$, separations tend to decline during labor market downturns, making them procyclical, which is when the quits effect dominates.

Throughout the rest of this paper, we define the vacancy rate as the ratio of the number of vacancies to the number of employed persons, i.e. $v_{t}=V_{t} / E_{t}{ }^{7}$ Given this definition of the vacancy

\footnotetext{
${ }^{5}$ In section 3, when we present our results for our sample of countries, we show that the Beveridge curve that we construct for the U.S. does not line up very well with the data when one does not take into account the cyclicality of separation and assumes that $\alpha_{s}=0$.

${ }^{6}$ One way to interpret this equation is as the log-linearized reduced form equation of a model of frictional unemployment with unemployment, $U_{t}$, being the only state variable.

${ }^{7}$ This is slightly different from the definition used in JOLTS where $v_{t}=V_{t} /\left(V_{t}+E_{t}\right)$, which would make the vacancy rate conceptually equivalent to the unemployment rate. The problem with this definition is that it assumes that the unit of measurement
} 
rate, we show in the Appendix that combining the turnover steady state condition, (3), with the matching function, (4), and the equation that captures the cyclicality of the separation rate, (5), yields that

$$
g_{t+1}=e^{\mu_{h}+\varepsilon_{h, t}}\left(\frac{u_{t}}{1-u_{t}}\right)^{\alpha_{h}} v_{t}^{\left(1-\alpha_{h}\right)}-e^{\mu_{s}+\varepsilon_{s, t}}\left(\frac{u_{t}}{1-u_{t}}\right)^{\alpha_{s}} v_{t}^{-\alpha_{s}}
$$

We interpret the Beveridge curve as all combinations of $\left(u_{t}, v_{t}\right)$ that satisfy the above equation. Thus, the Beveridge curve is the implicit functional relationship between the unemployment and vacancy rates that satisfies the turnover steady-state condition.

Of course, this implicit relationship between the unemployment and vacancy rates only holds in the data if the labor market tends to be close to its steady state. Moreover, this relationship is only stable as long as (a) the growth rate of the labor force, $g_{t+1}$, is relatively constant, (b) there are no major changes in match efficiency, $\mu_{h}+\varepsilon_{h, t}$ and in the level of separations $\mu_{s}+\varepsilon_{s, t}$, and (c) the elasticities, $\alpha_{h}$ and $\alpha_{s}$, do not change over time.

We use equations (3), (4), and (5) to construct a fitted Beveridge curve for the U.S. First, we estimate the matching function, (4), and the cyclicality of separations, (5), using OLS to obtain estimated values for $\mu_{h}, \alpha_{h}, \mu_{s}$, and $\alpha_{s}{ }^{8}$ We then construct a fitted Beveridge curve by solving for the combinations of $u_{t}$ and $v_{t}$ that satisfy (6) evaluated at the estimated parameters $\mu_{h}, \alpha_{h}, \mu_{s}$, and $\alpha_{s}$, at the average growth rate of the labor force, and at $\varepsilon_{h, t}=\varepsilon_{s, t}=0$. Note that this way of constructing a fitted Beveridge curve does not involve any direct estimation of a relationship between the unemployment rate and the vacancy rate. This relationship is derived through the assumption of the labor market being close to its turnover steady state.

of the vacancy statistic is defined as a job comparable to those in the employment number. It turns out that in some of our source data this is not the case. Using the vacancy to employment ratio as a measure of the vacancy rate means that cyclical fluctuations in the rate are not dependent on the unit of measurement of vacancies.

${ }^{8}$ The application of OLS for the estimation of matching functions, (4), has been criticized (Borowczyk-Martins, 2013) because of the potential for endogeneity of the number of vacancies posted with respect to the level of match efficiency, $\varepsilon_{h, t}$. Of course, endogeneity bias is also a concern for the application of OLS to the reduced form equation (5). Unfortunately, the length of the annual time series, at maximum 17 observations, on which the cross-country results we present are based prevents us from applying econometric methods aimed at correcting for endogeneity. 


\section{The fitted U.S. Beveridge curve and its post-recession shift}

An updated version of the fitted pre-recession Beveridge curve from Barnichon et al. (2012) is plotted in Figure 1. ${ }^{9}$ As can be seen from the figure, the U.S. labor market only slightly deviated from its Beveridge curve from December 2000 through December 2007. Even during the depth of the Great Recession, when U.S. labor demand declined sharply, the U.S. labor market remained relatively close to the pre-recession turnover steady-state relationship.

However, in the middle of 2009, the U.S. Beveridge curve relationship started to change; the vacancy rate increased substantially while the unemployment rate barely declined. This is the same time at which the observed vacancy yield started falling short of that predicted by the estimated matching function. This can be seen from Figure 2. Since the end of the recession, hires per vacancy have been about 30 percent lower than the fitted pre-recession matching function would suggest. In terms of equation (4), this implies that $\varepsilon_{h, t} \approx-0.3$ over the three years preceding June 2012.

The decline in match efficiency in the U.S. is only one side of the coin, however. The other side is that separations also declined more than one would have expected based on their pre-recession comovements with the unemployment-to-vacancy ratio. This excessive decline in separations is due to people staying put in their jobs and not quitting to pursue other opportunities. Figure 3 shows that since mid-2009 quits have been about 15 percent lower than predicted by their pre-recession cyclicality. In terms of equation (5), this indicates that $\varepsilon_{s, t} \approx-0.15$ over the last several years

In Figure 1, we recalculate the fitted Beveridge curve with the same parameters as the prerecession one except we set $\varepsilon_{h, t} \approx-0.3$ and $\varepsilon_{s, t} \approx-0.15$ to obtain the shifted Beveridge curve. It turns out that the actual realizations of the unemployment and job-openings rates over the past two years have been very close to this shifted curve. This suggests that the rightward shift in the U.S. Beveridge curve since the Great Recession is the result of changes in the rate of labor turnover rather than of a change in the growth rate of the labor force, $g_{t}$, or of the cyclicality of the vacancy yield and separation rate, captured by $\alpha_{h}$, and $\alpha_{s}$.

In particular the change in labor turnover that has caused the rightward shift is that many fewer persons are being hired per vacancy than implied by the estimated pre-recession matching function.

\footnotetext{
${ }^{9}$ This fitted curve is based on estimates of equation (4) and (5) using pre-2008 data. The exact specification of the equations used in Barnichon et al. (2012) is slightly different because they are tailored to the monthly JOLTS and CPS data available in the United States. See Barnichon et al. (2012) for details. The functional forms presented in this paper are the ones we subsequently implement in our cross-country analysis using annual OECD data.
} 
The effect of this decline in match efficiency on the Beveridge curve is reduced by the fact that fewer workers separate from their jobs, driven by a reduction in quits, thus needing fewer hires to maintain the same unemployment rate at a particular level of vacancies. On net, the decline in the vacancy yield has dominated the reduction in the separation rate and the Beveridge curve has shifted rightwards.

Rightward shifts in the Beveridge curve like the one in Figure 1 have, in the past, coincided with increases in the natural rate of unemployment. To see how big an increase in the natural rate of unemployment the current shift implies, it is important to put this Great Recession episode in a historical perspective. As Tasci and Lindner (2010) and Daly, Hobijn, Şahin, and Valletta (2012) point out, the current shift is not as big as the one in the 1970's and 1980's when the natural rate is estimated to have risen to 6.3 percent. ${ }^{10}$ Hence, based on that observation, it is not very likely that the current shift in the U.S. Beveridge curve results in a natural rate well above 6 percent. Using more formal time-series techniques, Dickens (2009), Fleischman and Roberts (2011), and Dickens and Triest (2012) reach a similar conclusion.

The effect of the shift in the Beveridge curve on the natural rate of unemployment largely depends on whether it is permanent or not. Various recent studies which examined the potential causes of the shift in Beveridge curve concluded that these factors are mostly transitory. We briefly discuss this literature here in the context of the declines in labor turnover as reflected by the reduction in match efficiency and the separation rate.

\section{Decline in match efficiency}

The persistent decline in measured U.S. match efficiency since the end of the recession has been widely documented. (See for example Barnichon et al., 2012, Borowczyk-Martins et al., 2013, Davis, Faberman, and Haltiwanger, 2012, Elsby, Hobijn, and Şahin, 2010, Sedláček, 2012) What has emerged from the many studies that have focused on different aspects of this decline is the following narrative.

The decline in house prices in the U.S. that set off the Great Recession resulted in a disproportionate decline in activity in sectors and demand for occupations with high labor turnover. This had two effects.

\footnotetext{
${ }^{10}$ This is the peak of the Congressional Budget Office's natural rate of unemployment estimates in 1978.
} 
The first effect was that the composition of the distribution of job openings shifted from sectors and occupations with high vacancy yields, like construction, to those with low vacancy yields, like health care and engineering. So, even if there had been no change in match efficiency in the sectorand occupation-specific labor markets, this shift led to a composition effect that reduces measured aggregate match efficiency. Industry-level studies, like Barnichon et al. (2012), and Davis, Faberman, and Haltiwanger (2012), find that a large part of the negative impact of this composition effect on match efficiency is due to the drop in activity in the construction sector. The results in Hobijn (2012) suggest the shift in the occupational mix of job openings is actually more important than the cross-industry composition for the observed decline in match efficiency.

This composition effect is amplified by the fact that it results in an increase mismatch between the vacancies posted and the pool of unemployed. The two most commonly considered dimensions of this mismatch is in terms of: $(i)$ the skills required to fill the vacancies posted and those supplied by the unemployed, and (ii) the fact that job openings might be posted in different regions than were the unemployed reside.

Studies that construct a formal index of skill mismatch (Şahin et al., 2013, Dickens and Triest, 2012, and Lazear and Spletzer, 2012b) all find that mismatch increased during the recession but has since almost returned to its pre-recession level. In terms of the effect of mismatch on the unemployment rate, Şahin et al. (2013) show that the increase in skill mismatch accounts for about a third of the run-up of the unemployment rate during the depth of the recession. ${ }^{11}$

Measures of geographic mismatch indicate that it has not played an important role in the decline in match efficiency in the wake of the Great Recession. Such measures do not capture, however, that the same level of geographic mismatch might result in higher labor market frictions in the wake of a decline in house prices. This is because homeowners who have negative equity in their homes are less likely to relocate to take a job, in case they are unemployed, or switch jobs, in case they are employed. Most studies that aim to quantify the importance of this "house lock" effect tend to find it is very small. This is true both for empirical studies (Molloy, Smith, and Wozniak, 2011,

\footnotetext{
${ }^{11}$ There is a growing theoretical literature that provides models in which match efficiency endogenously fluctuates over the business cycle due to the variation in the composition of the pool of unemployed. Sedláček (2012) and Ravenna and Walsh (2013) both provide models in which firms are more picky in selecting workers during times of high unemployment than during times of tightness in the labor market.
} 
Schulhofer-Wohl, 2012, and Valletta, 2010) as well as those based on more formal labor market models with search frictions (Sterk, 2012, and Karahan and Rhee, 2013).

The depth of the Great Recession led the U.S. Congress to enact the temporary Emergency Unemployment Compensation, which increased the duration of unemployment insurance benefits from 26 weeks up to 99 weeks. Since such an extension of benefits may reduce the job search effort of job seekers and/or prolong labor force attachment of UI recipients, it can potentially explain the rightward shift in the Beveridge curve. While the estimates of the effects of UI extensions on the unemployment rate range from 0.3-1.7 percentage points, most studies find an effect of around 1 percentage point or less. (See Aaronson, Mazumder, and Schecter, 2010; Farber and Valletta, 2011; Fujita, 2010; Nakajima, 2012; Rothstein, 2011; Valletta and Kuang, 2010). For example, Daly, Hobijn, and Valletta (2011) focus on the comparison of the duration of unemployment for individuals who are eligible or not eligible for UI receipts and find that the increase in duration was larger for UI eligibles. They argue that even if one fully attributes this difference to UI eligibility, only about 0.8 percentage points of the increase in the unemployment rate is due to extended UI benefits.

\section{Decline in quits}

We have shown that the decline in quits partially offsets the effect of the decline in match efficiency in terms of the rightward shift in the Beveridge curve. However, this decline is not necessarily an improvement since it is indicative of a substantial decline in the rate of reallocation of workers in the U.S. labor market. As Lazear and Spletzer (2012a) point out, such churning is an important part of the process of creative destruction that moves resources from less productive to more productive economic activities.

In a related paper, Saint-Paul (1995), following an argument in Blanchard and Summers (1998), introduces a model in which a decline in quits makes firms more reluctant to hire in the first place when there are costs to firing workers. He shows that such a feedback effect between quits and hires has the potential to generate multiple labor market equilibria. In a slightly generalized version of his model, movement from a low unemployment/high labor turnover to a high unemployment/low labor turnover equilibrium would result in both a decline in the quits rate as well as measured match efficiency. 
Moreover, Diamond (2013) argues that a large decline in quits skews the pool of job seekers towards the unemployed, thus mechanically reducing the number of hires per unemployed and measured match efficiency. This is because, since a measure of the number of persons who are searching on-the-job is not available, the number of unemployed is used as a proxy for the number of job seekers in the matching function, (4).

Because (i) a large part of the sectoral shifts during recessions that drive the change in the composition of the distribution of vacancies and increases mismatch tends to be cyclical rather than structural in nature (Abraham and Katz, 1986; Şahin et al., 2013), (ii) the rate of adjustment of the U.S. labor market is very high (Elsby, Hobijn, and Şahin, 2013), (iii) U.S. workers are very mobile across industries and occupations (Hobijn, 2012), and (iv) UI extensions are temporary, the current rightward shift in the U.S. Beveridge curve is likely to largely reverse over the coming years.

In short, recent studies of the U.S. labor market indicate that the shift in the U.S. Beveridge curve is mostly due to transitory factors. Of course, the U.S. is not the only country $(i)$ that saw a run up in unemployment in the wake of the Great Recession, (ii) that experienced a drop in house prices, an associated reduction in residential investment, and a decrease in the demand for construction workers, (iii) whose government responded to the financial crisis by increasing the generosity of UI benefits, (iv) where the rate at which workers quit and move to other jobs slowed down since 2007. In the rest of this paper we consider whether these factors have also resulted in movements in the Beveridge curves in other countries.

This requires the construction of fitted Beveridge curves for countries other than the U.S., for which we introduce a new methodology in the next section.

\section{Beveridge curve shifts since 2007 for 14 OECD countries}

In order to examine shifts in the Beveridge curves across countries we need to construct fitted Beveridge curves for countries other than the U.S. The main problem is that direct measures of 
labor turnover, like hires and separations from the JOLTS for the U.S., are not available for other countries. $^{12}$

However, estimates of hires and separations can be constructed using data on the number of employees by job tenure. The most direct way of doing so is to measure the number of hires in a year as the number of workers who, at the end of the year, are on a job with tenure shorter than 12 months. This is the methodology applied in OECD (2009). This way of measuring hires ignores the workers who get hired in a year and separate from their jobs before the end of the year. Thus, such a measure would underestimate the amount of turnover in the labor market.

To overcome this undercounting, we introduce a way to use the published numbers on job tenure distributions to impute total hires and separations, taking into account that the turnover in jobs that takes place within a year. In the first part of this section we introduce our method to construct time series for hires and separations across countries. In the second part we combine these time series with those on unemployment and vacancies and estimate matching functions as well as the cyclicality of separations for the 13 countries in our sample. In the next part, we then use these estimates to obtain fitted pre-Great-Recession Beveridge curves in the same way as discussed in Section 2. Finally, we consider the deviations from these fitted curves that occurred since the start of the Great Recession.

\section{Estimating hires and separations using annual data on employment by job tenure}

Time, $t$, is continuous and measured in years. Total employment at time $t$ is given by $E_{t}$. We also keep track of the number of workers who were employed at the beginning of the year and are still in the same job at the end of the year. These workers, by definition, have a job tenure, $\tau$, longer than a year at the end of the year, and we denote them by $E_{t}^{\tau>1}$.

Our imputation method assumes that firms hire at a constant rate over the year. That is, the number of hires at any time is equal to $h E_{t}$, where $E_{t}$ is the level of employment and $h$ is the hires rate. Those who were employed separate from their jobs at the rate $s$. Both $h$ and $s$ are annualized continuous-time flow rates. For these two turnover rates, we assume that they are constant over year $t$, i.e. over $(t, t+1]$.

\footnotetext{
12 The only other country for which we found data on hires and separations is Japan, where annual time series for hires and separations have been published as part of the Survey of Employment Trends done by the Japanese Ministry of Health, Labour, and Welfare since 1952 .
} 
In Appendix A, we show that, given $E_{t}, E_{t+1}$, and $E_{t+1}^{\tau>1}$, one can solve for the implied hires rate $h$, and the separation rate, $s$. The solution is given by

$$
h=\ln \left(E_{t+1}\right)-\ln \left(E_{t+1}^{\tau>1}\right)
$$

and

$$
s=\ln \left(E_{t}\right)-\ln \left(E_{t+1}^{\tau>1}\right) .
$$

These are estimates of continuous-time flow rates. Given that we have data at an annul frequency, we are interested in the actual flows implied by these rates. As we show in Appendix A, these flows can be calculated by time aggregating the continuous-time flows. This yields that the total number of hires and separations over the year, $H_{t}$ and $S_{t}$, is equal to

$$
H_{t}=\left(\frac{h}{h-s}\right)\left[e^{(h-s)}-1\right] E_{t} \quad \text { and } \quad S_{t}=\left(\frac{s}{h-s}\right)\left[e^{(h-s)}-1\right] E_{t} .
$$

Thus, for countries and years for which we have observations on the fraction of workers with a job tenure longer than a year as a fraction of total employment in the next year, total employment in that year, and total employment in the next year, we can calculate an estimate of total hires and separations during the year using equations (7), (8), and (9).

These estimates of hires and separations are similar to the estimates of total flows into and out of unemployment for OECD countries introduced in Elsby, Hobijn, and Şahin (2013), who tailor the method used in Shimer $(2005,2012)$ to impute monthly unemployment inflow and outflow rates for the U.S. to the available data for a broad set of OECD countries. ${ }^{13}$

Annual data on employment levels are available for all OECD countries as part of the OECD's Annual Labour Force Statistics. In addition, the OECD publishes annual data on employment by job tenure intervals for many countries. For most of the European countries with available data, these series go back to the early 1990's when Eurostat started collecting job tenure data as part of the European Labour Force Survey. Data for Australia cover years as far back as $1986 .{ }^{14}$ Biannual data

\footnotetext{
${ }^{13}$ Similar to the unemployment inflow and outflow measures in Elsby, Hobijn, and Şahin (2013) which are affected by the duration dependence of unemployment outflow hazards, our estimates here are affected by the tenure dependence of job separation rates. We discuss in the appendix how this mainly affects the level of the turnover measures and not the cyclical fluctuations that are of interest for the rest of our analysis.

${ }^{14}$ For Australia, we supplement the OECD data with data from the Australian Bureau of Statistics' Labour Mobility release.
} 
for the U.S. are available from 1996 onwards. ${ }^{15}$ For Japan, direct measures of labor turnover are available starting in 1952.

\section{Matching functions and cyclicality of separations}

The time series of hires and separations allow us to estimate pre-Great-Recession matching functions, (4), and the cyclicality of separations, (5). This can be done for countries for which data on vacancies are available.

We draw upon two sources for our job vacancy data. Our main source is the OECD's Job Vacancies Statistics. We supplement it with data from Eurostat for some countries since 2008 for which no data from the OECD are available. ${ }^{16}$ The sample of advanced economies for which we have the data required for the estimation of (4) and (5) and have data through 2011 consists of 13 countries. The U.S. is one of these 13. We include the U.S. in our analysis to allow for a comparison of the results in Section 2, based on JOLTS data, with those obtained using the employment by job tenure data.

Table 1 contains the estimated parameters $\alpha_{h}$ and $\alpha_{s}$, as well as their standard errors and the $R^{2}$ 's associated with the regressions for the 13 countries in our sample. ${ }^{17}$ The last column (VII) shows the number of annual observations on which the results are based.

For most countries, our estimates of hires and separations based on employment by job tenure data go back to 1991. Because we end the sample in 2007, we have 17 annual observations for these countries before the Great Recession. For the U.S., the data are biannual, while for Austria and Sweden, they start later than 1991.

For France and Japan, we deliberately use a sample that starts later than the start date of the data. Both these countries saw a noticeable shift in their Beveridge curves during the period for which we have data. Because we aim to estimate fixed labor turnover equations that underlie a

\footnotetext{
${ }^{15}$ The U.S. data are taken from the Displaced Workers and Job Tenure supplement that is part of the Current Population Survey (CPS). We use the data available every two years since 1996. Before 1996 the job tenure question was phrased in an ambiguous way that makes it hard to interpret it as a continuous job tenure.

${ }^{16}$ This is the case for Spain and Portugal. For Portugal the fluctuations in the vacancy data published by the OECD and Eurostat are very different. We use the Eurostat data here because those give the smallest deviation from the Beveridge curve, which we already argue to be large.

${ }^{17}$ We do not report the intercepts, $\mu_{h}$ and $\mu_{S}$, because they depend on the units of measurement of vacancies which differ across countries. This makes comparison of these parameters hard to do.
} 
stable fitted Beveridge curve, we start the estimation for France and Japan after the Beveridge curve shifts; in 1996 and 2001 respectively.

For the U.K., we use all available observations through 2008 but we allow for a change in the units of measurement of vacancies that coincides with a break in the U.K. vacancy series in 1998. The details of how we take this into account can be found in the Appendix.

In spite of the relatively small sample sizes and the annual frequency of the data, we obtain positive estimated match elasticities with relatively small standard errors for all countries in the sample (Table 1, Columns I-III). For 9 out of the 13 countries, more than half of the variation in the vacancy yield is explained by the log variation in labor market tightness $\left(R^{2}>.5\right.$ in column III of Table 1).

The estimates of the matching function elasticity of unemployment based on the annual employment by job tenure data from the OECD are quite similar across countries. Estimates of the elasticity $\alpha_{h}$ across countries vary from 0.12 for Japan to 0.83 for Austria while half of the estimated elasticities, $\alpha_{h}$, are in the range of $0.40-0.55$, with a median of $0.48{ }^{18}$

There is much less similarity across countries in the estimated cyclicality of separations (Columns IV and V of Table 1). Moreover, as can be seen by comparing the $R^{2}$ 's in columns III and VI of Table 1, fluctuations in labor market tightness explain a much smaller fraction of movements in separations than in hires. This is not surprising because the degree and sign of the cyclicality of separations depend on the relative importance of quits and layoffs.

For most countries, though, we find that separations are procyclical, i.e. $\alpha_{s}<0$. They increase when the labor market is tight and $u / v$ is low and they decrease when there is a lot of slack and $u / v$ is high. The only two countries where separations are not procyclical are Austria, where they seem acyclical (as Hall, 2005, conjectured to be the case for the U.S.), and Spain, where we find significant countercyclicality of separations.

The latter suggests that in Spain, more than in other countries, it is the fluctuations in layoffs over the business cycle and not quits that drive separations from employment. This is likely the

\footnotetext{
${ }^{18}$ It is worth noting that the results for the two countries with the lowest estimated $\alpha_{h}$ 's are not based on annual data on employment by job tenure. Instead, the results for the U.S. and Japan are based on biannual data and a direct measure of hires respectively. The range 0.12-0.83 is similar to the range of estimates surveyed by Petrongolo and Pissarides (2001, Table 3). The estimate of 0.27 for the U.S., is much smaller than the one of 0.58 obtained using the monthly JOLTS data, that are the source of Figure 2, and is also smaller than the estimated matching function elasticity for the U.S. of 0.72 in Shimer (2005), which uses an estimate of the outflow rate out of unemployment rather than hires.
} 
result of the disproportionate reliance on temporary labor contracts in Spain's dual labor markets. Such contracts are often not renewed in a downturn and drive up the cyclicality of layoffs (Costain et al., 2010, OECD, 2012).

On the whole, our results imply that only considering hires does not suffice for the analysis of the dynamics of labor turnover in OECD countries. The cyclical fluctuations in separations imply that quits are an important driving force of variations in labor turnover and thus of the turnover steady-state relationship between the unemployment and vacancy rates. ${ }^{19}$

\section{Fitted Beveridge curves}

We use the estimates of $\mu_{h}, \alpha_{h}, \mu_{s}$, and $\alpha_{s}$ from Table 1 to fit pre-recession Beveridge curves for the countries in our sample by solving for the unemployment rate/vacancy rate locus that solves the turnover-steady-state equation (3). We evaluate (3) at the average growth rate of the labor force between 1990 and 2012 and set $\varepsilon_{h, t}=\varepsilon_{s, t}=0$. The fitted curves are shown in Figure 4, for the U.S., and Figure 5 for all 12 other countries.

We start by considering the fitted Beveridge curve based on the data on employment by job tenure for the U.S. in Figure 4. Doing so allows us to compare it to the fitted curve from Figure 1, which is based on monthly JOLTS data.

Compared to Figure 1, which shows the JOLTS sample from 2001-2011, Figure 4 contains a longer time series on vacancies that covers 1960-2011. The grey dots are annual pre-2008 observations that are not used for the estimation of the parameters in Table 1. The black dots are the observations for the years for which labor turnover estimates are available which are used in the estimation results listed in Table 1 . The black squares are observations since 2008. The numbers next to them indicate the year.

The black dashed line is the fitted Beveridge curve based on the seven biannual observations for which we have data on employment by job tenure for the U.S. Even though the fitted curve is only based on 7 observations, it is remarkably similar to the fitted curve in Figure 1. Just like in Figure 1, the fitted curve shows that before the Great Recession, the U.S. had a relatively stable Beveridge curve and that during the recession, the labor market seemed to move along this curve. It was during

\footnotetext{
${ }^{19}$ This finding is in line with the results in Hagedorn and Manovskii (2013) and Daly et al. (2012) which both suggest that job-to-job transitions are crucial for understanding cyclical fluctuations in real wages.
} 
the recovery that started in the summer of 2009 that the U.S. unemployment-vacancy relationship started to deviate from the stable relationship it exhibited in the decade before.

In addition to the fitted Beveridge curve, Figure 4 also contains another curve. The grey dashed line, labeled "Fitted - constant separations," is the imputed turnover-steady-state $u / v$-locus when one does not take into account the cyclicality of separations and sets $S / E$ equal to its sample average in equations (3) and (6). The reason we included this line is to show how important it is to take into account the cyclicality of separations to understand the shape of the Beveridge curve. ${ }^{20}$ As can be seen from the figure, ignoring the cyclicality of separations leads to an estimated turnover steady-state unemployment-vacancies relationship that is very different from the observations in the data.

The panels in Figure 5 show the equivalent of Figure 4 for the other countries in our sample. For most countries the fitted Beveridge curve traces out the $(u, v)$ sample observations well. Of course, this is a judgment about the distance of the sample observations from the fitted curves. Because we will discuss distances from the fitted Beveridge curves throughout the rest of our analysis, it is worthwhile to formally introduce them here.

We define the fitted Beveridge curves as the implicit function $u_{b c}(v)$ which gives the unemployment rate on the Beveridge curve as a function of the vacancy index. The horizontal distance of a point $\left(u_{t}, v_{t}\right)$ from the fitted Beveridge curve is then defined as

$$
D_{t}=\left(u_{t}-u_{b c}\left(v_{t}\right)\right)
$$

Throughout, we compare these distances with the square root of the sum of squared distances for the points for which the curve is fitted, which is given by

$$
\sqrt{\frac{1}{n} \sum_{t \in \text { sample }} D_{t}^{2}}
$$

where $n$ is the number of observations listed in Column VII of Table 1. If the fitted Beveridge curve was a (non-linear) regression line, then this could be interpreted as the standard error of the residuals and thus as a measure of goodness of fit. ${ }^{21}$

\footnotetext{
${ }^{20}$ Ignoring the cyclicality of separations for the construction of the fitted JOLTS-based Beveridge curve of Figure 1 yields a very similar curve to the grey dashed line in Figure 4.

${ }^{21}$ Since the fitted curve is a locus constructed based on estimates of (4) and (5) and the average distance for the sample observations does not have to be zero this is not literally a standard error of the residuals. However, in the rest of our analysis we will informally treat it as such.
} 
Column VII of Table 2 lists the value of (11) for all 13 countries in our sample. Except for Belgium, Portugal, and Spain, the value of (11) is smaller than 1.5 percentage points for all countries in the sample.

Belgium, Portugal, and Spain are countries with very slow unemployment adjustment dynamics. $^{22}$ This means that the labor markets in these countries are subject to larger and more persistent deviations from their labor-turnover steady states. As a result, because the fitted Beveridge curve is an estimate of the steady-state $(u, v)$-locus, one would expect bigger deviations from the curve in these countries than in others.

Besides the sample observations, the fitted steady-state relationships also capture out-of-sample observations in the latter part of the sample ('95 onwards) as well. For example, the high points on Austria's Beveridge curve and the low points on the Dutch curve all are points that were not part of the sample for which the matching function and cyclicality of separations were estimated.

So far, we focused on the black circles in Figures 4 and 5 and discussed the fitted curves. We now turn our attention to the black squares, which represent the observations since the onset of the Great Recession.

\section{Shifts in Beveridge curves since 2007}

Table 2 lists the main results related to the outcomes since the start of the Great Recession for the 13 countries in our sample. Columns I and II contain the level of the unemployment rate in 2011 and its percentage point change between 2007 and 2011. As can be seen from Column II, not all countries saw a large run-up in unemployment during the recession. Portugal, Spain, the U.K., and the U.S. are the countries with the largest increase in their unemployment rates from 2007-2011.

Columns VIII and IX of Table 2 list the distance of the post-recession observations for 2010 and 2011 from the fitted Beveridge curves. As can be seen from these columns as well as from Figures 4 and 5, in almost all countries, except for Belgium, Germany, and Japan, the post-recession observations are to the right of the fitted Beveridge curves. However, observations to the right of the curve are not unprecedented. They also occurred before the Great Recession.

To get a sense of how big these distances are compared to the in-sample deviations, we list the ratio of the 2010 and 2011 deviations and the approximate standard deviation of the in sample

\footnotetext{
${ }^{22}$ See Elsby, Hobijn, and Şahin (2008) for a discussion of these adjustment rates and for estimates for Spain and Portugal.
} 
horizontal distances, (11), in Columns $\mathrm{X}$ and XI. We report this ratio since they are in the spirit of a conventional Chow (1960) forecast test in which this ratio would have an actual $t$-distribution. ${ }^{23}$ Consistent with this $t$-test interpretation, we first focus on countries for which these ratios equal or exceeded 2 in both 2010 and 2011. The countries for which this is the case are Norway, Portugal, the U.K. and the U.S.

From our analysis in Section 2, we know that the post-recession deviations from the Beveridge curve in the U.S. are driven by the joint decline in match efficiency, i.e. $\varepsilon_{h}<0$ in (4), and decline in the cyclicality of separations, i.e. $\varepsilon_{S}<0$ in (5). Columns III-VI of Table 2 contain the crosscountry equivalent of $\varepsilon_{h}$ and $\varepsilon_{s}$ for 2010 both in levels as well as normalized by the standard error of the regressions. From these columns it can be seen that, just like the JOLTS data, our job-tenure based labor turnover estimates yield substantial declines in match efficiency as well as in the cyclicality of job separations in 2010 .

In addition to the U.S., the countries that saw a rightward shift in their Beveridge curve in the wake of the Great Recession (Norway, Portugal, and the U.K.) are among the countries with the highest decline in estimated match efficiency. In addition, Norway and the U.K. also saw their separation rate decline more than expected. In this sense, the deviations from the pre-recession curves in Norway and the U.K. mimic those in the U.S. in that they are driven by a decline in match efficiency partly offset by a reduction in quits. Instead of partly offsetting the decline in match efficiency, separations in Portugal, presumably layoffs, actually contributed to the rightward deviation from the fitted Beveridge curve.

Among Norway, Portugal, Spain, the U.K., and the U.S., Norway is an outlier. Though the deviations from the fitted Beveridge curve in Norway are large compared to their historical magnitudes, they are small in absolute terms. (0.6 percentage points in 2011) Moreover, contrary to the other three countries, Norway only had a less than one percentage point run up in its unemployment rate and did not see a large decline in the number of vacancies posted. Because of this, we do not classify Norway as having seen a large rightward shift in its Beveridge curve.

To show what Portugal, Spain, the U.K., and the U.S. have in common, Table 3 reports several cross-country statistics on unemployment insurance (Columns I and II) and on house prices and

\footnotetext{
${ }^{23}$ The limited number of observations in our sample and the fact that the distances, $D_{t}$, are not really regression residuals prevent us from doing a more formal statistical analysis.
} 
construction employment (Columns III-V). Where Portugal, Spain, the U.K., and the U.S. stand out is in the last two columns. These are the countries that were most severely hit by the housing crisis, causing both the steepest house price declines of the countries in our sample as well as large drops in the share of construction employment.

Because house price declines and job losses in the construction sector are highly correlated across countries, this evidence does not directly allow us to distinguish between geographical mismatch, on the one hand, and the composition effect and skill mismatch due to the displacement of a large number of construction workers, on the other.

As we discussed in Section 2, we know from the analyses that were specifically done for the U.S. that there is ample evidence that the decline in construction employment has reduced measured match efficiency and that geographical mismatch and house lock have not significantly reduced labor market turnover in the U.S.. As for the composition effect and skill mismatch in the other countries, Bonthuis et al. (2013) find that declines in the share of construction employment are an important factor explaining Beveridge curve shifts in the euro area. Direct evidence on mismatch for European countries is limited. For the U.K., Patterson et al. (2013) find, similar to for the U.S., that, at the occupational level, mismatch rose sharply during the recession, but then quickly fell towards a value slightly higher than its pre-recession level before rising again through 2011. They also find no evidence of a worsening in geographical mismatch in the U.K..

Even though there is not much direct evidence on geographical mismatch for other countries, it is reasonable to infer that it is not likely to be very important in shaping unemployment dynamics during the Great Recession. European countries typically have considerably lower mobility rates relative to the U.S. In Europe, the U.K. has a higher mobility rate than almost all the European countries we have data for (see Elsby, Hobijn, and Șahin, 2013). Given the findings on geographic mismatch for the U.S. and the U.K., we speculate that the role of geographic mismatch was negligible for other countries as well.

As can be seen from column II of Table 3, the U.S. is the only country in the sample with a substantial increase in the duration of unemployment insurance benefits. This, in combination with the evidence from the other columns of Table 3, leads us to conclude that the main drivers behind the Beveridge curve shifts in Portugal, Spain, the U.K., and the U.S. are the declines in match 
efficiency driven by the composition effect and increase in skill mismatch due to the displacement of a large number of workers, in particular those in the construction industry.

\section{Historical Perspective: Shifts between '75-'85 and '91-‘07}

The Beveridge curve shifts in the wake of the Great Recession are not the first. To put the deviations from the pre-recession curves since the start of the Great Recession in a better perspective, it is worthwhile to compare them with the historical shifts in the Beveridge curves that occurred in the 1980's.

We first consider the historical shift in the U.S. Beveridge curve, depicted in Figure 4. What stands out most is that the fitted pre-Great-Recession curve, based on data from 1996 through 2006, is on the left-hand side of the $(u, v)$-points in the diagram. This is because from the mid 1970's through the late 1980's, the U.S. Beveridge curve shifted outward. This outward shift coincided with the deep recessions of the early 1980's. This outward shift in the Beveridge curve during this period was not limited to the U.S.. Most other countries also saw their Beveridge curve shift outwards during this period. Where the U.S. experience stands out is that its Beveridge curve subsequently moved left. In most other countries movements in the 1980's were more persistent.

The panels in Figure 5 show the equivalent of Figure 4 for the other countries in our sample. As can be seen by comparing the fitted curve to the grey non-sample dots in all the panels, just like the U.S., all other countries saw a large rightward shift in their Beveridge curves.

Table 4 lists the level of the unemployment rate in 1985, the increase in the rate in the preceding decade, as well as the average distance of the 1975-1985 observations from the fitted Beveridge curves. As can be seen by comparing Column II of Tables 2 and 4, increases in unemployment rates during the deep recessions of the late 1970's and early 1980's were much more widespread and generally larger than those during the Great Recession. ${ }^{24}$

Rightward shifts in Beveridge curves following these deep recessions were also bigger and more widespread than those that we documented for the Great Recession. As can be seen from Column IV of the Table 4, the U.S. is the only country for which the fitted curve lies to the left of the 19751985 observations, by, on average, 3.7 percentage points on the unemployment rate to be precise.

\footnotetext{
${ }^{24}$ This comes with the caveat that in many countries the unemployment rate continued to increase after 2011 , the end of our sample.
} 
For all other countries, the fitted Beveridge curve is to the right of the 1975-1985 observations. Countries with the biggest movements are Spain, Belgium, Japan, France, and Germany. Comparison of Tables 2 and 4 shows that the magnitudes of these shifts are much bigger than the ones we observed during the Great Recession.

Though we are the first to formally quantify these shifts relative to the pre-Great-Recession curves, they have been analyzed and discussed in a large number of previous studies. The one most closely related to ours is Nickell et al. (2001). ${ }^{25}$ Two main reasons for these shifts have been pointed out.

The first is the change in the composition of the pool of unemployed, partly because of the change in the labor force due to the entry of the baby-boomers and partly because of the displacement of a large number of workers due to the depth of the recessions of the late 1970's and early 1980's. This is reminiscent of the skill mismatch argument related to construction employment for the recent shifts.

Entry of the baby-boomers in the labor market and an increase in female labor force participation drove a secular increase in frictional unemployment in the 1980's. As Shimer (1998) points out for the U.S., this composition effect largely reversed with the aging of the baby boomers. He attributes a large part of the inward shift in the U.S. Beveridge curve to this reversal. ${ }^{26}$

Pissarides (2006) discusses how the grey points on the right-hand side of the British Beveridge curve in Figure 5 can be interpreted as a prolonged counter-clockwise loop of the U.K. Beveridge curve, which reflect a slow adjustment of the British labor market after steep declines in manufacturing and mining employment in the 1980's resulted in the equivalent of the current construction-related mismatch.

The demographic trends and displacement of workers of the 1980's were widespread across many countries. The puzzle is then why the U.S. Beveridge curve shifted back while those of most other countries did not.

\footnotetext{
${ }^{25}$ Other cross-country analyses of these movements in the (u,v)-curve are Budd et al. (1987) and Bouvet (2012) for example.

${ }^{26}$ The replication files to Elsby, Hobijn, and Şahin (2010, figure 5) include results for a fully demographically adjusted unemployment rate. These results suggest that the adjusted for the 2010 composition of the U.S. labor force the U.S. unemployment rate would have been a bit more than 2 percentage points lower than the published number.
} 
Blanchard and Wolfers (2000) argue that this is because differences in labor market institutions/policies across countries made some countries more susceptible to a persistent unemployment problem after the deep recessions of the late 1970's and early 1980's than others.

Nickell et al. (2001, Table 10) present results that suggest that it is not only the labor market institutions and policies in place but also the change in them that contributed to the outwards shifts in the Beveridge curves in many countries. In particular, they find that countries that increased the durations of their unemployment benefits, not unlike the U.S. in 2008, saw a rightward shift in their $(u, v)$-relationships. ${ }^{27}$

Changes in labor market policies have also been pointed to as having contributed to a partial reversal of the Beveridge curve shifts of the 1980's in the Netherlands and the U.K. (Nickell and van Ours, 2000). The Netherlands and the U.K. are the two countries with the relatively smallest outward movement of their $(u, v)$-curves between 1975-1985 and the fitted sample (Table 4, columns III and VI). Nickell and van Ours emphasize that the reduction in unemployment in the Netherlands and the U.K. in the 1990's was a result of a combination of a reduction in the generosity of unemployment benefits and a transition to cooperative wage bargaining (in the U.K.: the Netherlands already had such a system). ${ }^{28}$

\section{Conclusion}

What emerges from a comparison of the evidence across countries and over time is a surprisingly consistent story. The displacement of a large part of the labor force during deep recessions results in a shift of the composition of vacancies and an increase in mismatch in the labor market which leads to a decline in measured match efficiency. This tends to be accompanied by a decline in the quits rate which partially offsets the effect of the reduction in match efficiency on the position of the Beveridge curve. The common policy response to reduce the burden of displacement for the unemployed by increasing the generosity and duration of unemployment insurance further contributes to the rightward shift of the Beveridge curve.

\footnotetext{
${ }^{27}$ In addition, they find that in countries where home ownership rates increased the Beveridge curve drifted outward. They interpret this as significant cross-country evidence of an effect of labor mobility on the Beveridge curve.

${ }^{28}$ In addition to the change in wage bargaining, Pissarides (2006) also discusses the change in monetary policy in the U.K. in 1993. He argues, on page 218, that the outward movement in the British Beveridge curve in the 1980's can be better interpreted as a prolonged counter-clockwise loop than an actual shift.
} 
As it turns out, the U.S. experience in the wake of the Great Recession perfectly fits this profile, with construction jobs being at the center of both the composition effect as well as the increase in skill mismatch. Going forward, the issue for the U.S. is then how quickly labor demand for high labor turnover jobs, like those in construction, recovers, how long the increase in skill imbalances between labor demand and labor supply in the market will last, and whether and when, as the economy recovers and mismatch unwinds, the extensions of UI will be allowed to expire.

Since $(i)$ a large part of the sectoral shifts during recessions that drive the change in the composition of the distribution of vacancies and increases mismatch tends to be cyclical rather than structural in nature, (ii) the rate of adjustment of the U.S. labor market is very high, (iii) U.S. workers are very mobile across industries and occupations, and (iv) UI extensions are not permanent, the current rightward shift in the U.S. Beveridge curve is likely to largely reverse over the coming years. This is not unlike, and will probably be faster than, the prolonged loop in the U.K. Beveridge curve in the late 1980's discussed by Pissarides (2006).

The labor market dynamics in the U.S. are the exception compared to other countries. In countries like Portugal and Spain, which have much slower rates of labor market adjustment and have permanently more generous UI benefits, the current rightward shift of the Beveridge curve is bound to be much longer-lasting than the one in the U.S. 


\section{References}

Aaronson, Daniel, Bhashkar Mazumder, and Shani Schechter (2010), "What is behind the rise in long-term unemployment?" Federal Reserve Bank of Chicago Economic Perspectives, 2Q/2010: 28-51.

Abraham, Katharine G., and Lawrence F. Katz (1986), “Cyclical Unemployment: Sectoral Shifts or Aggregate Disturbances?” Journal of Political Economy, 94, 507-522.

Akerlof, George A., Andrew K. Rose, and Janet L. Yellen (1988), "Job Switching and Job Satisfaction in the U.S. Labor Market," Brookings Papers on Economic Activity, 1988(2): 495582.

Barnichon, Regis, and Andrew Figura (2010), "What Drives Movements in the Unemployment Rate? A Decomposition of the Beveridge Curve," Finance and Economics Discussion Series 2010-48, Federal Reserve Board of Governors.

Barnichon, Regis, Michael W. L. Elsby, Bart Hobijn and Ayșegül Șahin (2012) "Which Industries are Shifting the Beveridge Curve?" Monthly Labor Review, June 2012, 25-37.

Blanchard, Olivier J., and Lawrence H. Summers (1988), "Beyond the Natural Rate Hypothesis," American Economic Review, Papers and Proceedings, 78, pp. 182-187.

Blanchard, Olivier J., and Justin Wolfers (2000), "The Role of Shocks and Institutions in the Rise of European Unemployment: The Aggregate Evidence," Economic Journal, 110, C1-C33.

Borowczyk-Martins, Daniel, Grégory Jolivet, and Fabien Postel-Vinay (2013) “Accounting For Endogeneity in Matching Function Estimation," Review of Economic Dynamics, 441-451.

Bonthuis, Boele, Valerie Jarvis, and Juuso Vanhala (2013), "What's Going on Behind the Euro Area Beveridge Curve?" mimeo, ECB.

Bouvet, Florence (2013), "The Beveridge Curve in Europe: New Evidence using National and Regional Data," Applied Economics, 44, 3585-3604.

Brügemann, Björn (2008) "What Elasticity of the Matching Function is consistent with U.S. Aggregate Labor Market Data?” mimeo, VU University Amsterdam.

Budd, Alan, Paul Levine, and Peter Smith (1987) "Long-Term Unemployment and the Shifting U-V Curve: A Multi-Country Study,” European Economic Review, 31, 296-305.

Burda, Michael C., and Jennifer Hunt (2011) "What Explains the German Labor Market Miracle in the Great Recession,” Brookings Papers on Economic Activity, vol. 42, Spring, 273-335.

Chow, Gregory C. (1960). "Tests of Equality between Sets of Coefficients in Two Linear Regressions," Econometrica, 52, 211-222.

Costain, James, Juan F. Jimeno, and Carlos Thomas (2013), "Employment Fluctuations in a Dual Labor Market," Bank of Spain Working Paper 1013.

Daly, Mary C., Bart Hobijn, and Rob Valletta (2011) “The Recent Evolution of the Natural Rate of Unemployment,” FRBSF Working Paper 2011-05. 
Daly, Mary C., Bart Hobijn, Theodore S. Wiles (2012) "Dissecting Aggregate Real Wage Fluctuations: Individual Wage Growth and the Composition Effect" FRB-SF Working Paper 2011-23.

Daly, Mary C., Bart Hobijn, Ayşegül Şahin, and Robert G. Valletta (2012) "A Search and Matching Approach to Labor Markets: Did the Natural Rate of Unemployment Rise?" Journal of Economic Perspectives, 26, Summer 2012, 3-26.

Davis, Steven J., R. Jason Faberman, and John C. Haltiwanger (2012) "Recruiting Intensity during and after the Great Recession: National and Industry Evidence," American Economic Review: Papers and Proceedings, forthcoming.

Diamond, Peter A. (2013), “Cyclical Unemployment, Structural Unemployment," NBER Working Paper \#18761.

Dickens, William T. (2009), "A New Method for Estimating Time Variation in the NAIRU," Understanding Inflation and the Implications for Monetary Policy: A Phillips Curve Retrospective, 205-228, MIT press.

Dickens, William T., and Robert K. Triest (2012), "Potential Effects of the Great Recession on the U.S. Labor Market," B.E. Journal of Macroeconomics, vol. 12, issue 3, 1-41.

Elsby, Michael W.L., Bart Hobijn and Ayșegül Șahin (2013) "Unemployment Dynamics in the OECD," The Review of Economics and Statistics, May 2013, 530-548

Elsby, Michael W.L., Bart Hobijn and Ayșegül Șahin (2010) "The Labor Market in the Great Recession," Brookings Papers on Economic Activity, Spring 2010, 1-48.

Fahr, René, and Uwe Sunde (2009) "Did the Hartz Reforms Speed-Up the Matching Process? A Macroevaluation using Empirical Matching Functions," German Economic Review, 10, 284316.

Farber, Henry S., and Robert G. Valletta (2011), "Extended Unemployment Insurance and Unemployment Duration in The Great Recession: The U.S. Experience," mimeo, Federal Reserve Bank of San Francisco and Princeton University, June.

Fleischman, Charles A., and John M. Roberts (2011) "From Many Series, One Cycle," Finance and Economics Discussion Series 2011-46, Board of Governors of the Federal Reserve System.

Fujita, Shigeru (2010), "Effects of the UI Benefit Extensions: Evidence from the Monthly CPS." Working Paper No. 10-35, Federal Reserve Bank of Philadelphia, November.

Hagedorn, Marcus, and Iourii Manovskii (2013), "Job Selection and Wages over the Business Cycle," American Economic Review, 103, 771-803

Hall, Robert E. (2005), "Job Loss, Job Finding, and Unemployment in the U.S. Economy over the Past Fifty Years," NBER Macroeconomics Annual 2005, ed. Mark Gertler and Kenneth Rogoff, 101-37. Cambridge, MA: MIT Press.

Hobijn, Bart (2012), "The Industry-Occupation Mix of U.S. Job Openings and Hires," FRB SF Working Paper 2012-09. 
Jacobi, Lena, and Jochen Kluve (2007), "Before and after the Hartz reforms: The performance of active labour market policy in Germany," IAB Zeitschrift für ArbeitsmarktForschung - Journal for Labour Market Research, 40, 45-64.

Karahan, Fatih, and Serena Rhee (2013), "Geographical Reallocation and Unemployment during the Great Recession: The Role of the Housing Bust," Federal Reserve Bank of New York Staff Reports 605.

Lazear, Edward P., and James R. Spletzer (2012a) "Hiring, Churn, and the Business Cycle," American Economic Review, Papers and Proceedings, 102, 575-79.

Lazear, Edward P., and James R. Spletzer (2012b) "The United States Labor Market: Status Quo or A New Normal?" mimeo, Stanford University.

Molloy, Raven, Christopher L. Smith, and Abigail Wozniak (2011) "Internal Migration in the US," Journal of Economic Perspectives, 25, 173-196.

Mortensen, Dale T. (1994), "The Cyclical Behavior of Job and Worker Flows," Journal of Economic Dynamics and Control, 18, 1121-1142.

Nakajima, Makoto (2012), "A quantitative Analysis of Unemployment Benefit Extensions," Journal of Monetary Economics, 59, 686-702.

Nickell, Stephen, and Jan van Ours (2000) "Falling Unemployment: The Dutch and British Cases," Economic Policy, 15, 136-180.

Nickell, Stephen, Luca Nunziata, Wolfgang Ochel, and Glenda Quintini (2001) "The Beveridge Curve, Unemployment and Wages in the OECD from the 1960s to the 1990s - Preliminary Version," Centre for Economic Performance Discussion Paper 502, London School of Economics and Political Science.

Organization for Economic Cooperation and Development (OECD) (2009), "How Do Industry, Firm and Worker Characteristics Shape Job and Worker Flows?" OECD Economic Outlook 2009: Tackling the Jobs Crisis, Paris: OECD.

Organization for Economic Cooperation and Development (OECD) (2012), "How Does Spain Compare?" OECD Employment Outlook 2012, Paris: OECD.

Patterson, Christina, Ayșegül Șahin, Giorgio Topa, and Gianluca Violante (2013) "Mismatch Unemployment in the U.K.," mimeo.

Pollock, Alex J. (2010), "Testimony on the Comparison of of International Housing Finance Systems," Senate Committee on Banking, Housing, and Urban Affairs, September 29, 2010

Petrongolo, Barbara, and Christopher A. Pissarides (2001), "Looking into the Black Box: A Survey of the Matching Function.” Journal of Economic Literature, 39, 390-431.

Pissarides, Christopher A. (2006), "Unemployment in Britain: A European Success Story," in Structural Unemployment in Europe: Reasons and Remedies, Martin Werding (ed.), Chapter 9, 209-236.

Ravenna, Federico, and Carl E. Walsh (2013), "Labor Market Flows with Skill Heterogeneity in a Monetary Policy Model.” Journal of Money Credit and Banking, forthcoming. 
Rothstein, Jesse (2012) "Unemployment Insurance and Job Search in the Great Recession." Brookings Papers on Economic Activity, Fall 2011, 143-196.

Șahin, Ayșegül, Joseph Song, Giorgio Topa, and Gianluca Violante (2013), "Mismatch Unemployment," Working paper, New York University.

Saint-Paul, Gilles (1995), “The High Unemployment Trap,” Quarterly Journal of Economics, 110, 527-550.

Schulhofer-Wohl, Sam (2012) "Negative Equity Does Not Reduce Homeowners' Mobility," FRB Minneapolis Quarterly Review, 35, 2-14.

Sedláček, Petr (2012), “Match Efficiency and Firms' Hiring Standards,” Working paper, Journal of Monetary Economics

Schmieder, Johannes F., Til von Wachter, and Stefan Bender (2012), "The Effects of Extended Unemployment Insurance Over the Business Cycle: Evidence from Regression Discontinuity Estimates over Twenty Years," Quarterly Journal of Economics, forthcoming.

Shimer, Robert (1998), "Why Is the U.S. Unemployment Rate so Much Lower?" NBER Macroeconomics Annual, 13, 11-16.

Shimer, Robert (2005), "The Cyclical Behavior of Equilibrium Unemployment and Vacancies," American Economic Review, 95, 25-49.

Shimer, Robert (2012), "Reassessing the Ins and Outs of Unemployment," Review of Economic Dynamics, 15, 127-148.

Sterk, Vincent (2012), "Home Equity, Mobility, and Macroeconomic Fluctuations,” DNB Working Paper No. 265.

Tasci, Murat, and John Lindner (2010) "Has the Beveridge Curve Shifted?" FRB Cleveland Economic Trends 08-10.

Valletta, Robert G. (2005) "Why Has the U.S. Beveridge Curve Shifted Back? New Evidence Using Regional Data," FRB SF Working Paper 2005-25.

Valletta, Robert G. (2010) "House Lock and Structural Unemployment," mimeo, FRB San Francisco.

Valletta, Robert G., and Katherine Kuang (2010) "Extended Unemployment and UI Benefits," FRB SF Economic Letter 2010-12. 


\section{Appendix A: Mathematical derivations}

\section{The Beveridge curve as an implicit function}

The estimated matching function that fits the vacancy yield, $H / V$, as a function of the unemployment to vacancy ratio, $U / V$ is given by

$$
\ln \left(H_{t} / V_{t}\right)=\mu_{h}+\alpha_{h} \ln \left(U_{t} / V_{t}\right)+\varepsilon_{h, t} .
$$

This implies that hires per employee equals

$$
\ln \left(H_{t} / E_{t}\right)=\mu_{h}+\alpha_{h} \ln \left(U_{t} / E_{t}\right)+\left(1-\alpha_{h}\right) \ln \left(V_{t} / E_{t}\right)+\varepsilon_{h, t} .
$$

Since the unemployment to employment ratio can be written in terms of the unemployment rate as

$$
\frac{U_{t}}{E_{t}}=\frac{u_{t}}{1-u_{t}}
$$

and because we define the vacancy rate as $v_{t}=V_{t} / E_{t}$, the estimated matching function implies that we can write the ratio of hires per employee as

$$
\frac{H_{t}}{E_{t}}=e^{\mu_{h}+\varepsilon_{h, t}}\left(\frac{U_{t}}{E_{t}}\right)^{\alpha_{h}} v_{t}^{\left(1-\alpha_{h}\right)} .
$$

Similarly, since we estimate the cyclicality of separations using the iso-elastic functional form

$$
\ln \left(S_{t} / E_{t}\right)=\mu_{s}+\alpha_{s} \ln \left(U_{t} / V_{t}\right)+\varepsilon_{s, t},
$$

we can write this in terms of the unemployment and vacancy rates as

$$
\frac{S_{t}}{E_{t}}=e^{\mu_{s}+\varepsilon_{s, t}}\left(\frac{U_{t}}{E_{t}}\right)^{\alpha_{s}} v_{t}^{-\alpha_{s}}
$$

Combining (15) and (17), and the turnover steady-state condition (3) yields that the combinations of the unemployment rate and vacancy rate that are on the Beveridge curve need to satisfy

$$
g_{t+1}=e^{\mu_{h}+\varepsilon_{h, t}}\left(\frac{U_{t}}{E_{t}}\right)^{\alpha_{h}} v_{t}^{\left(1-\alpha_{h}\right)}-e^{\mu_{s}+\varepsilon_{s, t}}\left(\frac{U_{t}}{E_{t}}\right)^{\alpha_{s}} v_{t}^{-\alpha_{s}}
$$

which is the equation in the main text. This defines the unemployment rate on the Beveridge curve as an implicit function of the vacancy rate. 


\section{Construction of labor turnover estimates using annual employment by job tenure data}

Our aim is to estimate the hires and separation rates for different countries over time. In this appendix we show how the hires and separation rates can be estimated using data on employment growth and on the fraction of workers that report to have a job tenure smaller than a year. Throughout, time $t$ is continuous and measured in years. We consider a year that runs from $t \in[0,1]$.

The parameters that we are interested in estimating are the monthly separation rate, $s$, and the the monthly hires rate, $h$. We assume that these rates are constant over the year. Our method uses data on employment at the beginning of the year in month $0, E_{0}$, and at the end of the year at $t=1$, $E_{1}$. Moreover, we also have data on the fraction of workers that have been employed at a job with tenure of less than a year at the end of the year. This fraction allows us to calculate the number of workers at the year with a job tenure shorter than a year, which we denote by $E_{1}^{\tau<1}$, where $\tau$ denotes job tenure in years.

With the assumed constant hires and separation rates, $h$ and $s$, the number of employed persons evolves according to

$$
\dot{E}_{t}=h E_{t}-s E_{t}
$$

Solving this differential equation results in the solution that

$$
E_{t}=e^{(h-s) t} E_{0} \text { for } t \in[0,1]
$$

Hence, the growth rate of employment is the difference between the hiring rate, $h$, and the separation rate, $s$.

As for the number of workers hired over the period $[0, t)$ who are still employed at time $t$, i.e. $E_{t}^{\tau \leq t}$, this stock evolves according to

$$
\dot{E}_{t}^{\tau \leq t}=h E_{t}-s E_{t}^{\tau \leq t} \text { for } t \in[0,1] \text { and where } E_{0}^{\tau<0}=0 \text {. }
$$

This is where the assumption that the separation rate is independent of job tenure comes in, since this equation assumes that the overall separation rate, $s$, applies to those with job tenures in the interval $[0, t)$.

Since we know the solution for $E_{t}$, we can solve the non-homogenous linear differential equation for $E_{t}^{\tau<t}$ to obtain that 
Hobijn and Şahin

$$
E_{t}^{\tau \leq t}=\left[1-e^{-h t}\right] E_{t}
$$

This equation does not depend on the separation rate because of the assumption that the same rate applies to those workers with short tenures as well as long tenure.

This equation thus implies that the share of workers with a job tenure of a year or less as a fraction of total employment at time $t=1$ satisfies

$$
\frac{E_{1}^{\tau \leq 1}}{E_{1}}=\left[1-e^{-h}\right]
$$

This is a very useful result, because it implies that, even if there are no direct data on the hires rate as in JOLTS for the United States, the hires rate can be inferred from the share of workers with short tenures. In particular, the monthly hires rate can be calculated using

$$
h=-\ln \left(1-\frac{E_{1}^{\tau \leq 1}}{E_{1}}\right) .
$$

Given this estimate of the hires rate, the separation rate can be inferred from the survivor rate of those employed at the end of last period. That is,

$$
S=-\ln \left(\frac{E_{1}^{\tau>1}}{E_{0}}\right)
$$

These are the estimates of the annualized hires and separation rates, equivalent to the ones reported in JOLTS.

These flow rates can be transformed into estimates of actually flows of hires and separations. Let $H_{t}$ be the total number of hires over the period $[0, t)$. These total flows are given by

$$
H_{t}=\int_{0}^{t} h E_{v} d v=\left(\frac{h}{h-s}\right)\left[1-e^{-(h-s) t}\right] E_{t}=\left(\frac{h}{h-s}\right)\left[e^{(h-s) t}-1\right] E_{0} \text { for } t \in[0,1]
$$

Similarly, the total number of separations over $[0, t), S_{t}$, can be calculated as

$$
S_{t}=\int_{0}^{t} s E_{v} d v=\left(\frac{s}{h-s}\right)\left[1-e^{-(h-s) t}\right] E_{t}=\left(\frac{s}{h-s}\right)\left[e^{(h-s) t}-1\right] E_{0} \text { for } t \in[0,1]
$$

These two flow measures satisfy the identity that the change in employment is the difference between total hires and total separations. That is,

$$
E_{t}-E_{0}=H_{t}-S_{t}
$$


The above derivations describe how data on the distribution of job tenures can be used to construct hires and separation measures that are conceptually the same as those measured on a monthly basis for the United States as part of JOLTS.

For the empirical implementation of these equations, we assume that $E_{1}$ is the employment level observed in the year after which $h$ and $s$ are the turnover rates. This is because the job tenure surveys are done in the first half of the year and thus, those with a job tenure smaller than 12 months generally were hired in the previous year.

\section{Similar cyclicality of turnover measures from JOLTS and employment by job tenure}

For our calculation, we assume that workers of all job tenures separate at the same rate $s$. We know this is, at best, an approximation since there is ample evidence that the separation rate from a job is declining in the tenure length. However, this tenure-dependence of the separation rate turns out to be of second-order importance for our calculation and ignoring it results in much simpler expressions.

In an extension of the methodology, we allowed for the separation rate of recently hired workers to be different from $\mathrm{s}$. This requires using additional data on employment by job tenure shorter than 6 months which turns out to be noisy across countries and also depends on when in the year the job tenure distribution is measured. ${ }^{29}$ When we applied this generalized method we got more noisy estimates of hires and separations.

What is, in particular, important for our calculation is not the level of hires and separations imputed from the data but the percent fluctuations over the business cycle. These fluctuations were highly correlated across both methodologies. Because of this, we present the result for the simpler methodology that is less subject to noise measures of employment with tenure less than half a year.

A final way to consider whether our method captures cyclical fluctuations in separations and hires reasonably well is to compare the biannual estimates for 1996 through 2010 for the U.S. with the direct measures from JOLTS. Figure A1 shows that the logs of the JOLTS and job-tenure-data based estimates of hires and separations comove a lot. The correlations between the hires measures is .99 and between the separations series 0.91 . Hence, the cyclical movements in job-tenure-based

\footnotetext{
${ }^{29}$ Seasonality is actually also an issue for the share of workers employed longer than a year.
} 
Hobijn and Şahin

estimates of labor turnover are highly correlated with direct measures of labor turnover from JOLTS.

\section{Taking into account break in U.K. vacancy series in 1998}

The U.K. vacancy statistics contain a structural break between 1998 and 2001. There are no data for 1999 and 2000 (the OECD data for this year have been interpolated). The units of measurement of vacancies in the U.K. seems to have changes between the pre- and post-break data. To take this break into account we include a dummy, $d_{t}$, in the estimated matching and separations functions which equals one for the pre-break data and zero for the post-break period.

We then estimate the matching and separation functions as

$$
\ln \left(H_{t} / E_{t}\right)=\mu_{h}+\alpha_{h} \ln \left(U_{t} / E_{t}\right)+\left(1-\alpha_{h}\right) \ln \left(V_{t} / E_{t}\right)+\gamma_{h} d_{t}+\varepsilon_{h, t}
$$

and

$$
\ln \left(S_{t} / E_{t}\right)=\mu_{s}+\alpha_{s} \ln \left(U_{t} / V_{t}\right)+\gamma_{s} d_{t}+\varepsilon_{s, t}
$$

Combining these two conditions yields two turnover-steady-state loci. One that holds for the prebreak definition of vacancies, i.e. $d_{t}=1$, and one that holds post-break, i.e. $d_{t}=0$.

Of course, this way of taking into account the break assumes that the only thing that changed in terms of the vacancy measure is its unit of measurement and not its cyclical properties. 
Figure 1. The U.S. Beveridge curve: Dec 2000 - Jun 2012.

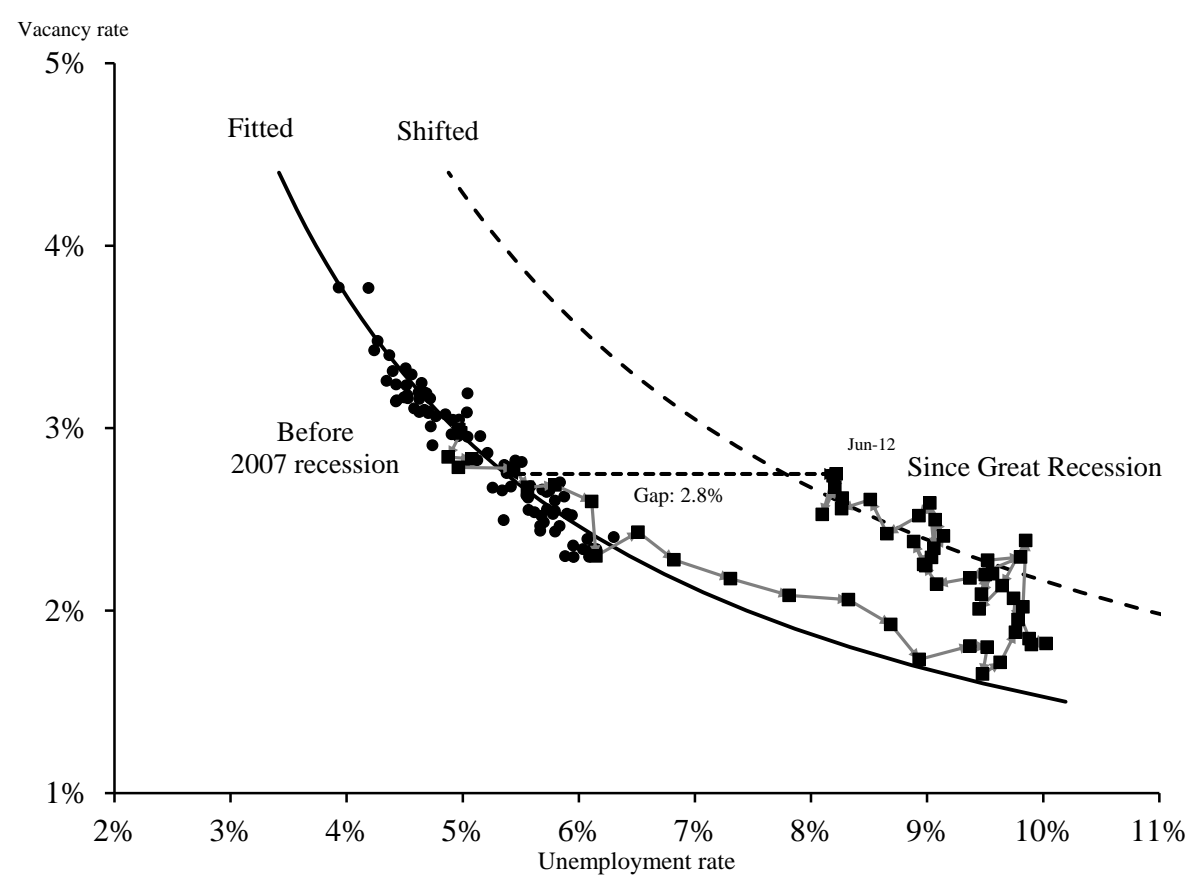

Source: JOLTS and authors' calculations, based on Barnichon et al. (2012).

Figure 2. Actual and fitted U.S. vacancy yield: Dec 2000 - Jun 2012.

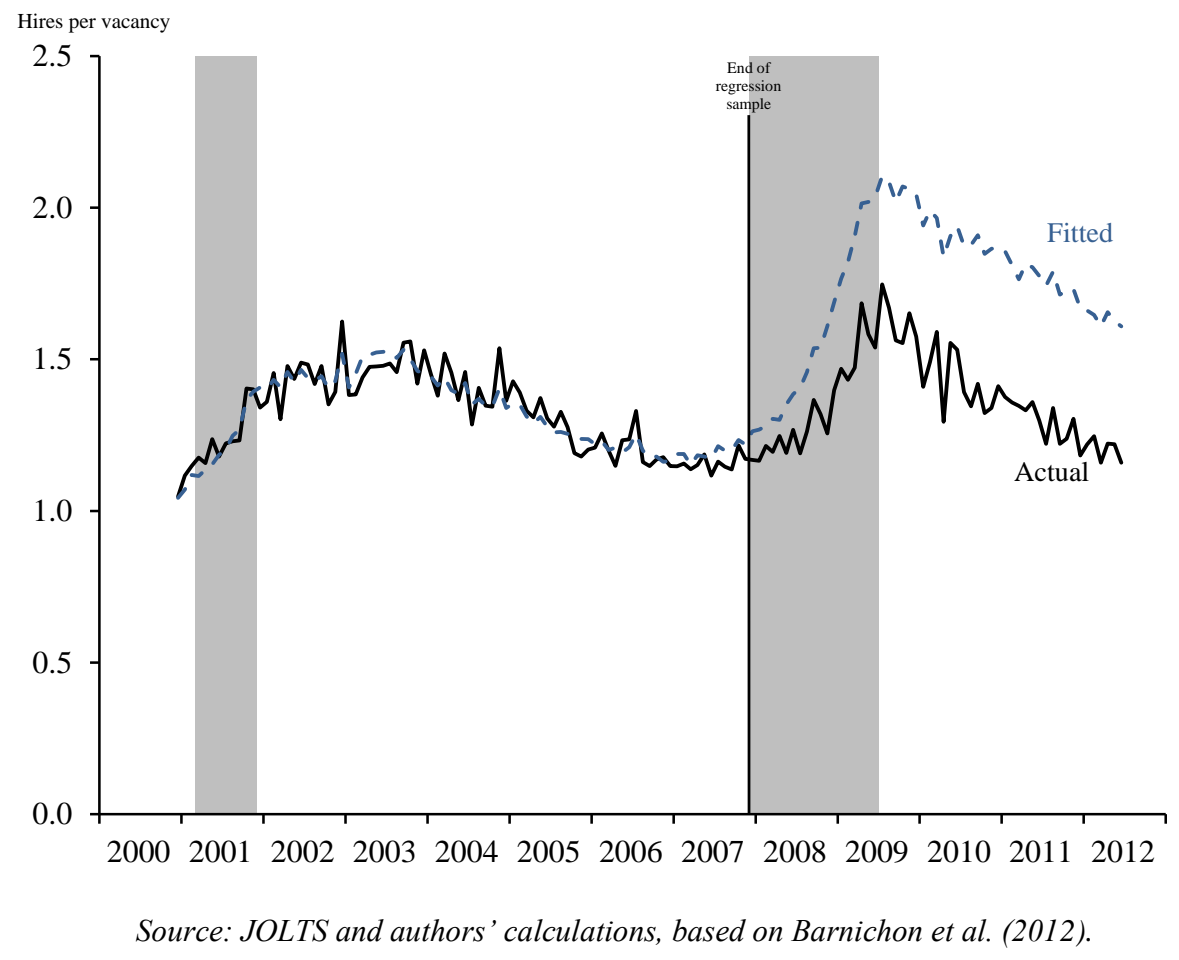


Hobijn and Şahin

Figure 3. Actual and fitted U.S. quits rate: Dec 2000 - Jun 2012.

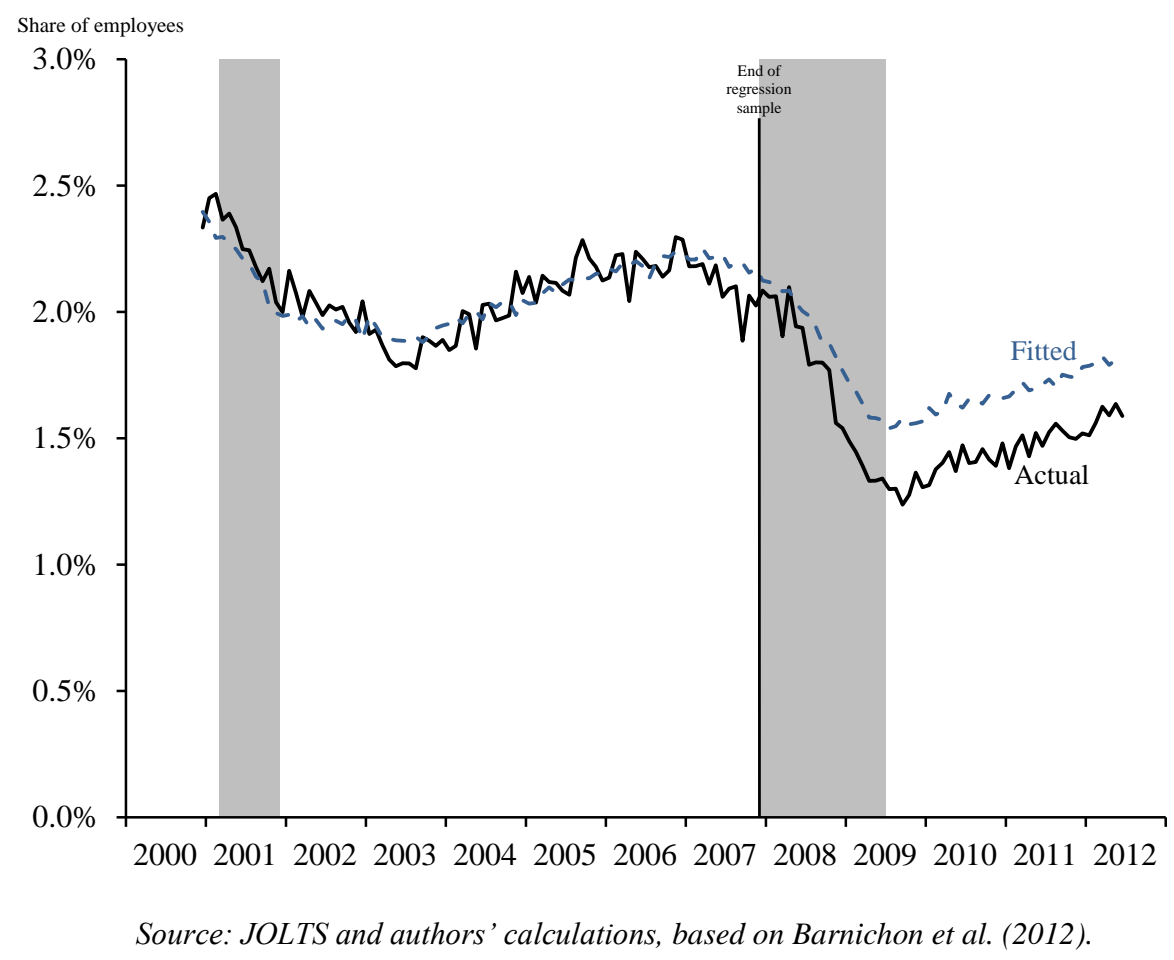

Figure 4. Actual and fitted U.S. Beveridge curve, job tenure data methodology, 1960-2011.

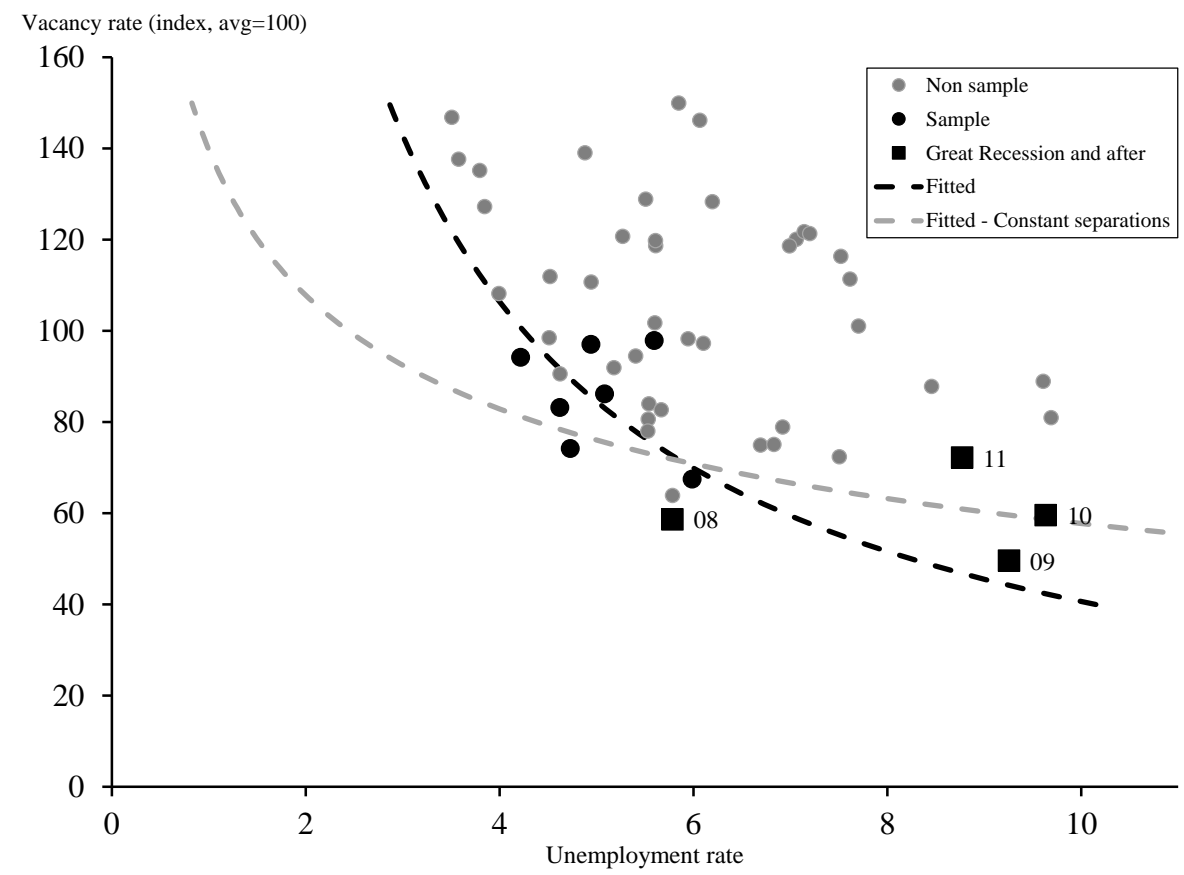

Note: The grey dashed line is the fitted Beveridge curve in which cyclicality of separations is ignored in the sense that $\alpha_{s}=0$ and $\mu_{s}$ is the mean of the log of the ratio of separations to employment. 
Figure 5. Actual and fitted Beveridge curves across countries.
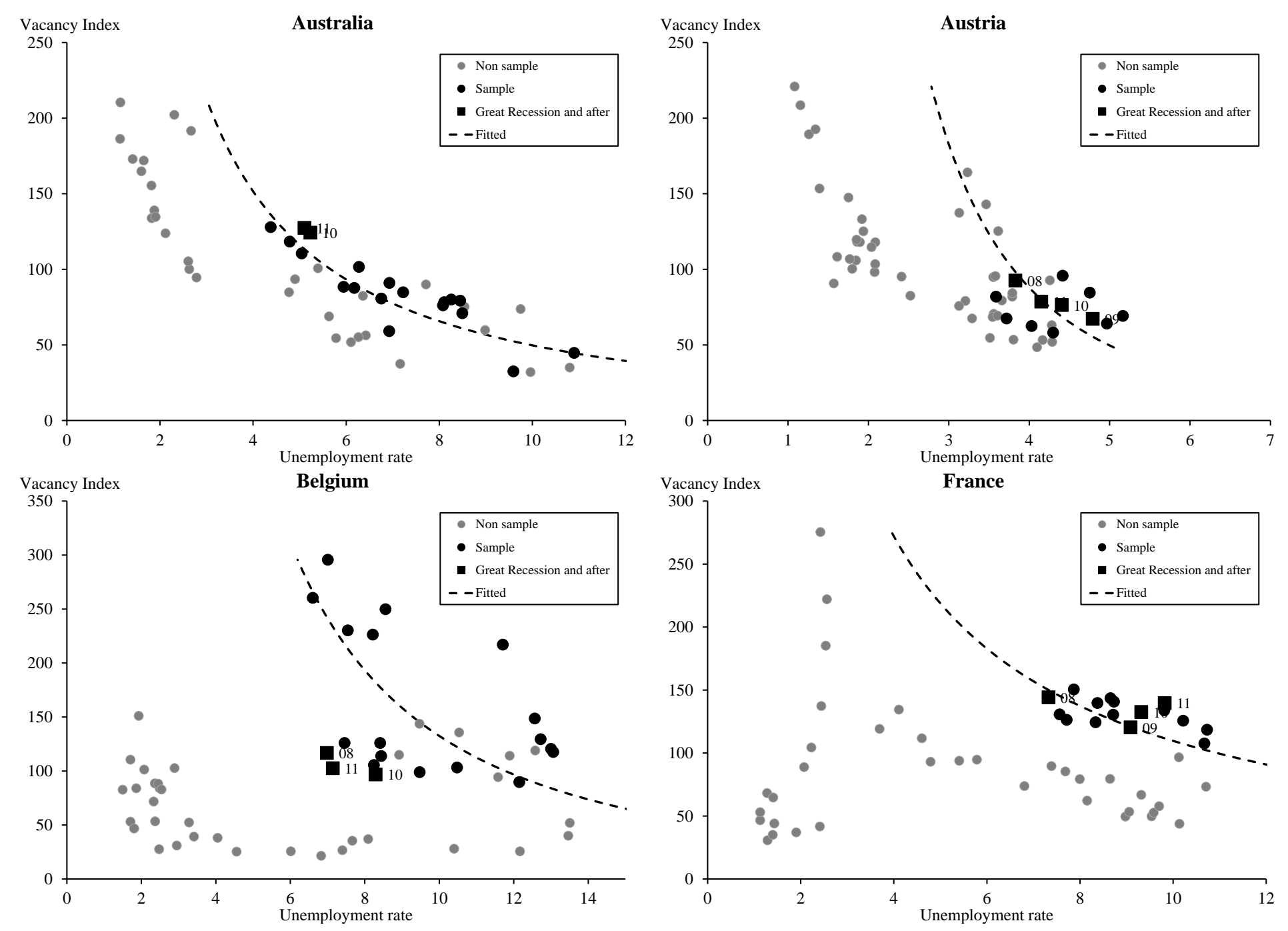

Note: Vacancy index is constructed to have an average of 100 over all observations plotted. 
Figure 5 (continued). Actual and fitted Beveridge curves across countries.
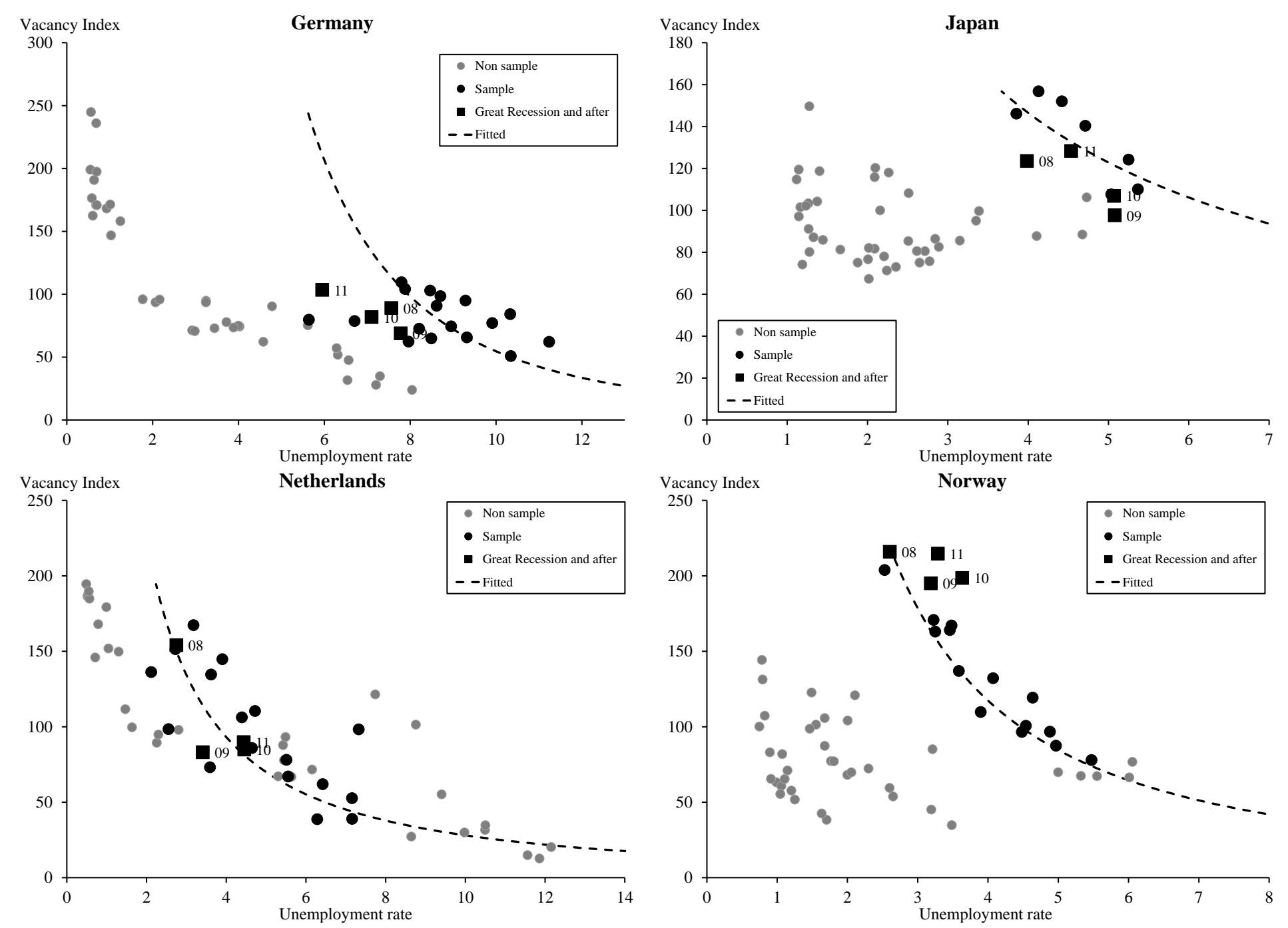

Note: Vacancy index is constructed to have an average of 100 over all observations plotted. 
Figure 5 (continued). Actual and fitted Beveridge curves across countries.
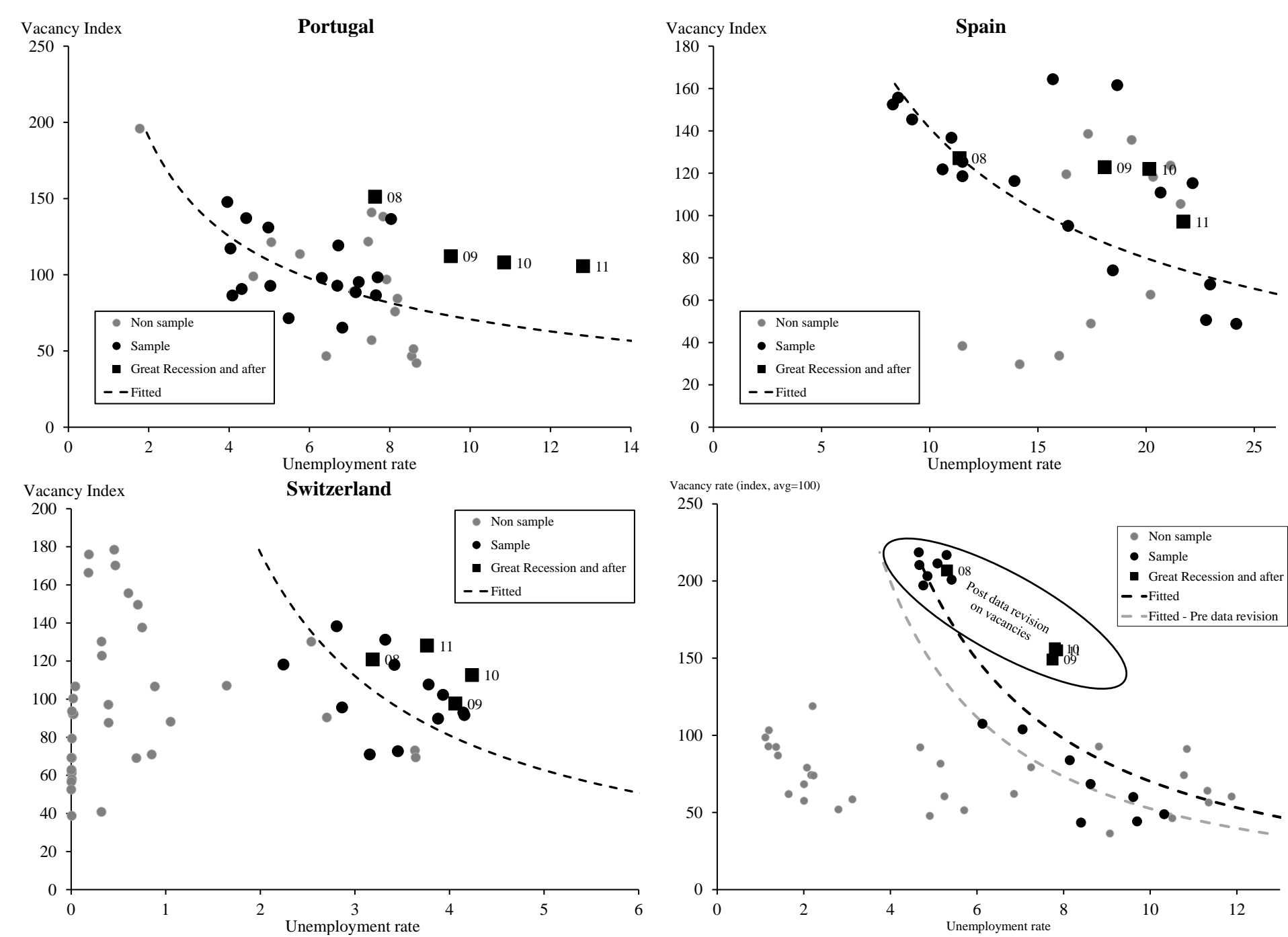

Note: Vacancy index is constructed to have an average of 100 over all observations plotted. For the U.K. the fitted Beveridge curves taking into account the structural break in U.K. vacancy statistics in 1998. The grey dashed line is the pre-break fitted Beveridge curve and the black dashed line the post-break one. See the appendix for details on how we dealt with the break. 
Hobijn and Şahin

Figure A1. Comparison of labor-turnover measures for the U.S.

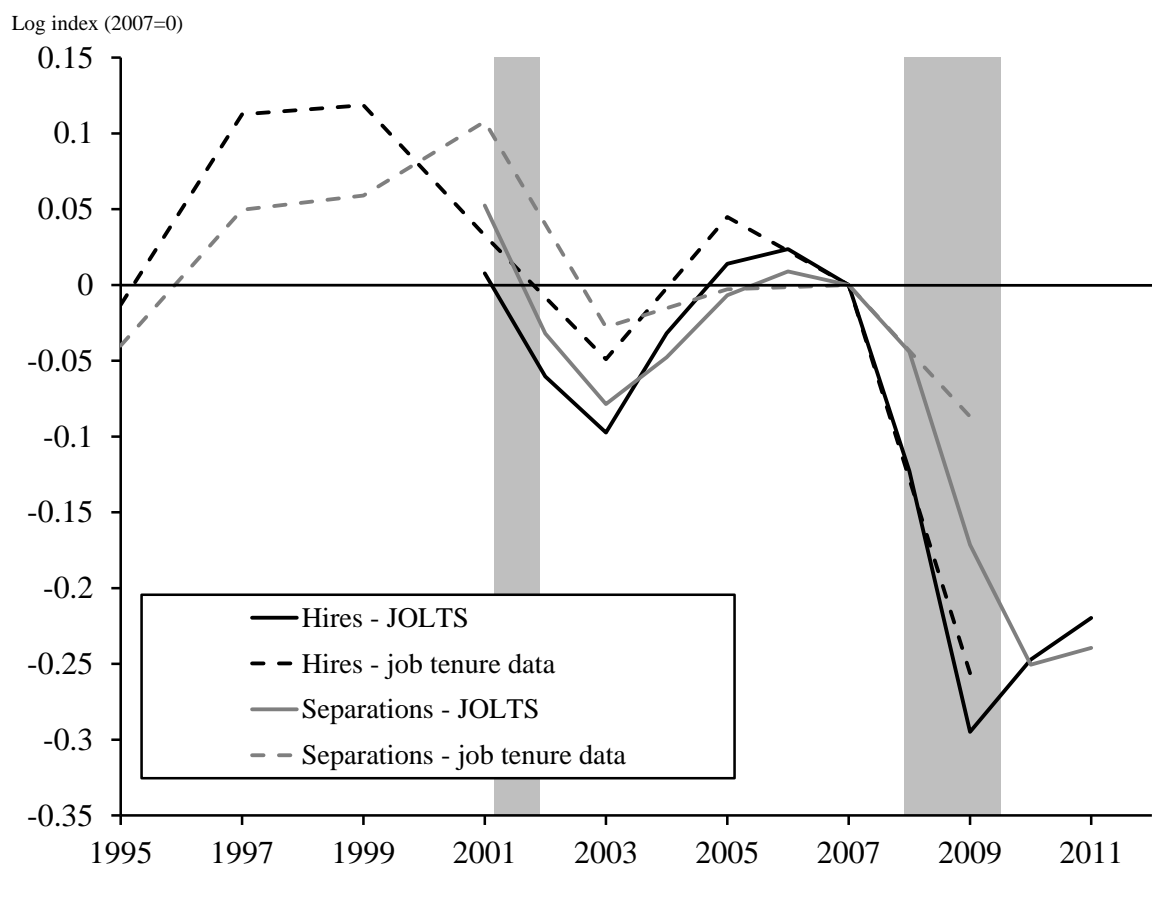

Source: JOLTS, OECD, and authors' calculations.

Note: JOLTS measures are annual data and job-tenure-data based measures are biannual. Series are log indices of hires and separations, normalized to equal 0 in 2007. 
Table 1. Estimated matching functions and cyclicality of separations.

\begin{tabular}{|c|c|c|c|c|c|c|c|c|}
\hline \multirow[b]{3}{*}{ No. } & \multirow[b]{3}{*}{ Country } & I & II & III & IV & $\mathrm{V}$ & VI & \multirow{3}{*}{$\begin{array}{c}\text { VII } \\
\text { Sample } \\
\text { size }\end{array}$} \\
\hline & & \multicolumn{3}{|c|}{ Vacancy yield } & \multicolumn{3}{|c|}{ Separation rate } & \\
\hline & & $\alpha_{h}$ & std.err. & $R^{2}$ & $\alpha_{s}$ & std.err. & $R^{2}$ & \\
\hline 1 & Australia & 0.53 & 0.04 & 0.91 & -0.01 & 0.04 & 0.00 & 17 \\
\hline 2 & Austria & 0.83 & 0.14 & 0.85 & 0.13 & 0.23 & 0.05 & 8 \\
\hline 3 & Belgium & 0.48 & 0.09 & 0.66 & -0.13 & 0.05 & 0.37 & 17 \\
\hline 4 & France & 0.24 & 0.09 & 0.39 & -0.25 & 0.05 & 0.69 & 12 \\
\hline 5 & Germany & 0.49 & 0.08 & 0.71 & -0.22 & 0.03 & 0.77 & 17 \\
\hline 6 & Japan & 0.12 & 0.08 & 0.32 & -0.31 & 0.11 & 0.62 & 7 \\
\hline 7 & Netherlands & 0.49 & 0.11 & 0.57 & -0.07 & 0.11 & 0.03 & 17 \\
\hline 8 & Norway & 0.46 & 0.09 & 0.70 & -0.13 & 0.09 & 0.16 & 14 \\
\hline 9 & Portugal & 0.23 & 0.11 & 0.24 & -0.14 & 0.09 & 0.14 & 17 \\
\hline 10 & Spain & 0.60 & 0.05 & 0.90 & 0.21 & 0.04 & 0.62 & 17 \\
\hline 11 & Switzerland & 0.41 & 0.12 & 0.54 & -0.12 & 0.06 & 0.27 & 12 \\
\hline 12 & United Kingdom* & 0.48 & 0.04 & 0.99 & -0.10 & 0.03 & 0.43 & 17 \\
\hline 13 & United States & 0.27 & 0.14 & 0.44 & -0.23 & 0.11 & 0.48 & 7 \\
\hline
\end{tabular}

Note: Estimated equations are $\ln (H / V)=\mu_{h}+\alpha_{h} \ln (U / V)$ and $\ln (S / E)=\mu_{h}+\alpha_{h} \ln (U / V)$,

where $H$ is hires, $S$ is separations, $U$ the total number of unemployed,E total employment, and $V$ is the stock of vacancies. All results based on OECD job tenure data.available before 2008. Except France where sample starts in 1996 and Japan where sample starts in 2001. We truncated these samples to avoid including shifts in Beveridge curve that occurred before these starting dates. Estimates of $\mu_{h}$ and $\mu_{s}$ are not reported because they vary across countries due to differing units of measurement of vacancies. The results for the U.K. allow for a structural break in the vacancy series in 1998. For details see the Appendix. 
Table 2. Change in unemployment rate, labor turnover residuals, and Beveridge curve shifts since 2007 across countries.

\begin{tabular}{|c|c|c|c|c|c|c|c|c|c|c|c|c|}
\hline \multirow[b]{4}{*}{ No. } & \multirow[b]{4}{*}{ Country } & I & II & III & \multicolumn{3}{|c|}{$\begin{array}{l}\text { abor turnover } \\
\text { residuals }\end{array}$} & VII & VIII & IX & $X$ & XI \\
\hline & & \multicolumn{2}{|c|}{ Unemployment rate } & \multicolumn{4}{|c|}{$\begin{array}{l}\text { Labor turnover } \\
\text { residuals }\end{array}$} & \multicolumn{5}{|c|}{$\begin{array}{c}\text { Distance from fitted } \\
\text { Beveridge curve }\end{array}$} \\
\hline & & $u_{t}$ & $\Delta u_{t}$ & $\varepsilon_{h, t}$ & $t_{h, t}$ & $\varepsilon_{s, t}$ & $t_{s, t}$ & $\frac{1}{n} \sqrt{\sum D_{t}^{2}}$ & $D_{t}$ & $D_{t}$ & $\frac{V I I I}{V I I}$ & $\frac{I X}{V I I}$ \\
\hline & & '11 & ‘07-‘'11 & '10 & ' 10 & ' 10 & ' 10 & sample & '10 & '11 & '10 & '11 \\
\hline 1 & Australia & 5.1 & 0.7 & & & & & 1.4 & 0.5 & 0.5 & 0.4 & 0.3 \\
\hline 2 & Austria & 4.2 & -0.3 & 14 & 1.6 & 16 & 1.2 & 0.6 & 0.2 & 0.0 & 0.3 & 0.0 \\
\hline 3 & Belgium & 7.1 & -0.3 & 41 & 2.1 & 21 & 2.0 & 2.2 & -3.7 & -4.5 & -1.6 & -2.0 \\
\hline 4 & France & 9.8 & 2.0 & -10 & -1.6 & -1 & -0.3 & 1.0 & 1.0 & 2.0 & 1.0 & 2.0 \\
\hline 5 & Germany & 5.9 & -2.8 & 16 & 1.5 & -14 & -3.5 & 1.3 & -1.5 & -1.9 & -1.2 & -1.5 \\
\hline 6 & Japan & 4.5 & 0.7 & & & & & 0.5 & -0.9 & -0.2 & -1.7 & -0.4 \\
\hline 7 & Netherlands & 4.4 & 1.3 & 28 & 0.8 & 41 & 1.1 & 1.2 & 0.2 & 0.3 & 0.1 & 0.3 \\
\hline 8 & Norway & 3.3 & 0.8 & -30 & -1.9 & -17 & -1.1 & 0.3 & 0.8 & 0.6 & 3.0 & 2.3 \\
\hline 9 & Portugal & 12.8 & 4.8 & -19 & -1.1 & 38 & 2.5 & 2.3 & 5.8 & 7.5 & 2.5 & 3.2 \\
\hline 10 & Spain & 21.7 & 13.4 & -73 & -4.6 & -29 & -2.3 & 5.4 & 8.1 & 5.8 & 1.5 & 1.1 \\
\hline 11 & Switzerland & 3.8 & 0.3 & -10 & -0.8 & -1 & -0.1 & 0.7 & 1.2 & 1.1 & 1.8 & 1.6 \\
\hline 12 & United Kingdom & 7.9 & 2.6 & -34 & -6.2 & -19 & -3.9 & 0.9 & 2.0 & 2.0 & 2.1 & 2.1 \\
\hline 13 & United States & 8.8 & 4.1 & & & & & 0.7 & 2.6 & 3.0 & 3.9 & 4.4 \\
\hline
\end{tabular}


Table 3. Changes in UI benefits, separations, house prices, construction employment.

\begin{tabular}{|c|c|c|c|c|c|c|}
\hline \multirow[b]{3}{*}{ No. } & \multirow[b]{3}{*}{ Country } & I & II & III & IV & $\mathrm{V}$ \\
\hline & & \multicolumn{2}{|c|}{$\begin{array}{l}\text { Unemployment } \\
\text { Insurance }\end{array}$} & \multicolumn{3}{|c|}{$\begin{array}{c}\text { House prices and } \\
\text { construction employment }\end{array}$} \\
\hline & & $\begin{array}{c}\text { Maximum } \\
\text { duration } \\
\text { '07-'10 } \\
\text { (months) }\end{array}$ & $\begin{array}{c}\text { Change in } \\
\text { maximum } \\
\text { duration } \\
\text { '07-'10 }\end{array}$ & $\begin{array}{c}\text { Home } \\
\text { ownership } \\
\text { rate } \\
{ }^{\circ} 00 \mathrm{~s}\end{array}$ & $\begin{array}{c}\text { Change in } \\
\text { house } \\
\text { prices } \\
\text { '07-'10 }\end{array}$ & $\begin{array}{l}\text { Change in } \\
\text { construction } \\
\text { employment } \\
\text { '07-'10 }\end{array}$ \\
\hline 1 & Australia & & & 70 & 11.4 & 0.0 \\
\hline 2 & Austria & 9 & 0 & 56 & 0.6 & 0.6 \\
\hline 3 & Belgium & $\infty$ & 0 & 78 & 5.7 & 0.6 \\
\hline 4 & France & 24 & 1 & 57 & -4.7 & 0.4 \\
\hline 5 & Germany & 12 & 0 & 46 & 0.0 & 0.0 \\
\hline 6 & Japan & 9 & 0 & 61 & -5.2 & -1.0 \\
\hline 7 & Netherlands & 38 & 0 & 57 & -4.3 & -0.7 \\
\hline 8 & Norway & 24 & 0 & 77 & 0.8 & 0.1 \\
\hline 9 & Portugal & 24 & 0 & 76 & 4.5 & -2.3 \\
\hline 10 & Spain & 24 & 0 & 85 & -14.7 & -5.8 \\
\hline 11 & Switzerland & 18 & 0 & 35 & 9.8 & -0.5 \\
\hline 12 & United Kingdom & 6 & 0 & 67 & -10.3 & -0.7 \\
\hline 13 & United States & 23 & 17 & 67 & -16.9 & -1.7 \\
\hline
\end{tabular}

Note: Unemployment insurance data are from OECD Benefits and Wages: Policies. House price changes taken from OECD Economic Outlook Annex tables. Change in construction employment is percentage point change in construction employment as share of the sum of employment in construction, industry, and services $(O E C D$ ShortTerm Labour Market Statistics, 2012). Home ownership rates from Pollock (2010) and Department for Communities and Local Government for U.K. Homeownership statistics are reported for most recent year since 2001 for which data are available. See sources for additional detail. 
Table 4. Horizontal and vertical Beveridge curve shifts between '75-'85 and the fitted curves ('91-'07).

\begin{tabular}{|c|c|c|c|c|c|c|}
\hline \multirow[b]{4}{*}{ No. } & \multirow[b]{4}{*}{ Country } & \multirow{2}{*}{\multicolumn{2}{|c|}{$\begin{array}{l}\text { I } \\
\text { Unemployment } \\
\text { rate }\end{array}$}} & \multirow{2}{*}{\multicolumn{3}{|c|}{$\begin{array}{cc}\text { III } \\
\text { Distance from fitted } \\
\text { Beveridge curve }\end{array}$}} \\
\hline & & & & & & \\
\hline & & $u_{t}$ & $\Delta u_{t}$ & \multirow{2}{*}{$\frac{1}{n} \sqrt{\sum D_{t}^{2}}$} & \multirow{2}{*}{$\begin{array}{c}\bar{D} \\
\cdot 75-' 85\end{array}$} & \multirow{2}{*}{$\begin{array}{c}\frac{I I I}{I V} \\
\cdot 75-' 85\end{array}$} \\
\hline & & '85 & '75-'85 & & & \\
\hline 1 & Australia & 8.3 & 3.4 & 1.4 & -2.3 & -1.7 \\
\hline 2 & Austria & 3.6 & 1.8 & 0.6 & -1.5 & -2.6 \\
\hline 3 & Belgium & 12.6 & 8.0 & 2.2 & -12.2 & -5.4 \\
\hline 4 & France & 9.5 & 5.8 & 1.0 & -6.8 & -7.0 \\
\hline 5 & Germany & 7.3 & 3.3 & 1.3 & -5.1 & -4.0 \\
\hline 6 & Japan & 2.6 & 0.7 & 0.5 & -6.7 & -13.2 \\
\hline 7 & Netherlands & 10.5 & 5.2 & 1.2 & -0.5 & -0.4 \\
\hline 8 & Norway & 2.6 & 0.3 & 0.3 & -3.8 & -13.5 \\
\hline 9 & Portugal & 8.7 & 4.1 & 2.3 & -3.7 & -1.6 \\
\hline 10 & Spain & 21.6 & 16.9 & 5.4 & -24.3 & -4.5 \\
\hline 11 & Switzerland & 0.9 & 0.6 & 0.7 & -3.1 & -4.4 \\
\hline 12 & United Kingdom & 11.3 & 8.0 & 0.9 & -1.5 & -1.6 \\
\hline 13 & United States & 7.2 & -1.3 & 0.7 & 3.7 & 5.6 \\
\hline
\end{tabular}

Note: Sample statistics based on years for which job tenure data are available and are used to construct fitted Beveridge curves. $n$ in columns III is the sample size reported in column VII of Table 1. Statistics for 1975-1985 are for all years for which unemployment rate and vacancy rate data are available. 